\title{
Traditional Chinese Medicine Induced Liver Injury
}

\author{
Rolf Teschke \\ Department of Internal Medicine II, Division of Gastroenterology and Hepatology, Klinikum Hanau, Academic Teaching Hospital \\ of the Medical Faculty of the Goethe University Frankfurt/ Main, Germany
}

\begin{abstract}
Traditional Chinese Medicine (TCM) is popular around the world and encompasses many different practices with particular emphasis on herbal TCM. Using the PubMed database, a literature search was undertaken to assess the extent herbal TCM products exert rare hepatotoxicity. Analysis of reported cases revealed numerous specified herbal TCM products with potential hepatotoxicity. Among these were An Shu Ling, Bai Fang, Bai Xian Pi, Ban Tu Wan, Bo He, Bo Ye Qing Niu Dan, Bofu Tsu Sho San, Boh Gol Zhee, Cang Er Zi, Chai Hu, Chaso, Chi R Yun, Chuan Lian Zi, Ci Wu Jia, Da Chai Hu Tang, Da Huang, Du Huo, Gan Cao, Ge Gen, Ho Shou Wu, Hu Bohe You, Hu Zhang, Huang Qin, Huang Yao Zi, Hwang Geun Cho, Ji Gu Cao, Ji Ji, Ji Xue Cao, Jiguja, Jin Bu Huan, Jue Ming Zi, Kamishoyosan, Kudzu, Lei Gong Teng, Long Dan Xie Gan Tang, Lu Cha, Ma Huang, Mao Guo Tian Jie Cai, Onshido, Polygonum multiflorum, Qian Li Guang, Ren Shen, Sairei To, Shan Chi, Shen Min, Shi Can, Shi Liu Pi, Shou Wu Pian, Tian Hua Fen, White flood, Wu Bei Zi, Xi Shu, Xiao Chai Hu Tang, Yin Chen Hao, Zexie, Zhen Chu Cao, and various unclassified Chinese herbal mixtures. Causality was firmly established for a number of herbal TCM products by a positive reexposure test result, the liver specific scale of CIOMS (Council for International Organizations of Medical Sciences), or both. Otherwise, the quality of case data was mixed, especially regarding analysis of the herb ingredients because of adulteration with synthetic drugs, contamination with heavy metals, and misidentification. In addition, non-herbal TCM elements derived from Agaricus blazei, Agkistrodon, Antelope, Bombyx, Carp, Fish gallbladder, Phellinus, Scolopendra, Scorpio, and Zaocys are also known or potential hepatotoxins. For some patients, the clinical course was
\end{abstract}

Keywords: Traditional Chinese medicine; Traditional Chinese herbal medicine; Herbal hepatotoxicity; Herb induced liver injury; Herbs.

Abbreviations: ALP, alkaline phosphatase; ALPb, alkaline phosphatase baseline; ALPr, alkaline phosphatase reexposure; ALT, alanine aminotransferase; ALTb, alanine aminotransferase baseline; ALTr, alanine aminotransferase reexposure; AST, aspartate aminotransferase; CIOMS, Council for International Organization of Medical Sciences; CMV, cytomegalovirus; EBV, Epstein Barr virus; HAV, hepatitis A virus; HBV, hepatitis B virus; $\mathrm{HCV}$, hepatitis C virus; $\mathrm{HEV}$, hepatitis $\mathrm{E}$ virus; HILI, herb induced liver injury; HSV, herpes simplex virus; LTX, liver transplantation; $\mathrm{N}$, upper limit of normal; PA, pyrrolizidine alkaloid; $\mathrm{R}$, ratio; RUCAM, Roussel Uclaf Causality Assessment Methods; TAM, Traditional Asian Medicine; TCM, Traditional Chinese Medicine; TOM, Traditional Oriental Medicine; HSOS, hepatic sinusoidal obstruction syndrome; HVOD, hepatic veno-occlusive disease; VZV, varicella zoster virus.

Received: 17 January 2014; Revised: 27 February 2014; Accepted: 2 March 2014 DOI of original article: 10.14218/JCTH.2014.00003.

Correspondence to: Rolf Teschke, Department of Internal Medicine II, Klinikum Hanau, Academic Teaching Hospital of the Goethe University of Frankfurt/Main, Leimenstrasse 20, Hanau D-63450, Germany. Tel.: +49-6181/21859, E-mail: rolf. teschke@gmx.de severe, with risks for acute liver failure, liver transplantation requirement, and lethality. In conclusion, the use of few herbal TCM products may rarely be associated with hepatotoxicity in some susceptible individuals, necessitating a stringent pretreatment evaluation of the risk/benefit ratio, based on results of multicenter, randomized, double-blind, placebo-controlled clinical trials.

(C) 2014 The Second Affiliated Hospital of Chongqing Medical University. Published by XIA \& HE Publishing Ltd. All rights reserved.

\section{Introduction}

Traditional Chinese Medicine (TCM) is one of the oldest healing systems worldwide, originating in the ancient Chinese philosophy and dating back to more than 2,500 years. ${ }^{1,2}$ In other Asian countries, TCM became popular and is called Traditional Asian Medicine (TAM) or Traditional Oriental Medicine (TOM), and Kampo Medicine in Japan. Since these practices have been adopted in other parts of the world, technically the topic should be considered to be Traditional Chinese and other Asian Medicine. However, in Western countries, the use of the popular name TCM has remained virtually unchanged without naming each individual country engaged in Traditional Medicine originating from ancient China. The basic principles of TCM are identical or vary only little between the numerous countries. Therefore, the use of TCM as the overall term is warranted and facilitates the discussions around major TCM related issues.

TCM is not a single entity but encompasses many different practices, including herbal medicine, acupuncture, moxibustion, massage, dietary therapy, and physical exercise such as shadow boxing. ${ }^{1,2}$ TCM is a fully institutionalized part of China's health care system and is widely used within Western medicine. ${ }^{2}$ In 2006, the TCM sector included over 200 million outpatients and around seven million inpatients, accounting for $10-20 \%$ of health care in China. ${ }^{2}$ Although the exact number of people who use TCM in the United States is unknown, it was estimated in 1997 that some 10,000 practitioners served more than one million patients each year. ${ }^{1}$ Despite its popularity, there has been concern about the efficacy and safety of TCM, ${ }^{1-4}$ and other issues related to scattered and inappropriate randomized controlled clinical trials of TCM. ${ }^{2,4,5}$ Adverse reactions by TCM have been reported, leading to systemic and organ specific health risks $^{2,6}$ including the liver. ${ }^{7,8}$ These reactions create concern and represent a particular clinical challenge because TCM products are commonly perceived as natural and thereby erroneously as safe.

Hepatotoxicity by TCM is limited to natural products, mainly herbs, from the more than 7,000 Chinese herbal 
medications in use. ${ }^{8}$ Herb induced liver injury (HILI) is not restricted to Chinese herbs but may be commonly observed in virtually all countries where herbs are consumed. ${ }^{9}$ At present, HILI has been documented with published case reports or case series by at least 60 different herbs and herbal mixtures, including Chinese ones. In this review, a literature search was performed for cases of herbal TCM with special reference to hepatotoxic side effects and addressed the question of how to improve collection and evaluation of case data in the future in order to facilitate causality assessment.

\section{Literature search and identification of reports}

For a selective literature search from 1990 to 2013, PubMed was searched using the terms Traditional Chinese Medicine, Traditional Asian Medicine, Traditional Oriental Medicine, Traditional Chinese Medicine liver injury, Traditional Asian Medicine liver injury, Traditional Oriental Medicine liver injury, Chinese herbal hepatotoxicity, Chinese herbal liver injury, herbal hepatotoxicity, and herb induced liver injury. From each search, the first 25 publications underwent analysis for subject matter, data quality, and overall suitability. Citations in retrieved publications were searched for other yet unidentified case reports. The search was limited primarily to English-language case reports, case series, and clinical reviews. Full lengths publications in Chinese, Japanese, or other Asian languages were not considered, but their abstracts were used occasionally if provided in English.

\section{Individual cases}

The selected publications represented reports of cases with herbal TCM induced liver injury and originated from China including Hong Kong, Taiwan, Japan, Korea, Singapore, Thailand, Australia, Italy, Spain, France, the Netherlands, the United Kingdom, Iceland, Canada, the United States, and Argentina. Outside of China, only around 500 TCM herbs are commonly used, which is a small fraction of the medicinal herbs available. In China, this number is estimated to be more than $7,000^{8}$ or around 14,000 items. ${ }^{10}$ The present analysis includes data from a relatively low number of potentially hepatotoxic TCM products, only a few dozen herbal products and single herbs. However, non-English language publications were excluded from this review, and the information here is not an exhaustive summary of all information collected to date.

In general, evaluation of cases with suspected herbal TCM induced liver injury is challenging because numerous aspects need to be considered for a valid assessment (Table 1). ${ }^{11-15}$ This includes a liver specific causality assessment, preferentially with the scale of the Council for International Organizations of Medical Sciences (CIOMS), also called the Roussel Uclaf Causality Assessment Method (RUCAM). ${ }^{13-15}$ Although rarely available, most valuable for the causality evaluation is the assessment of unintentional reexposures, which requires the application of strict criteria (Table 2). ${ }^{16,17}$

\section{An Shu Ling}

A 42-year old woman from the United States took three different herbal medicines for insomnia. ${ }^{18}$ The products were An Shu Ling (syn. Jin Bu Huan) as TCM, "Ignatia Amara", and "Relaxed Wanderer". Following a ten week treatment course, she experienced jaundice and developed acute hepatitis. A toxicology database found the synonym Jin Bu Huan listed for An Shu Ling,

L-tetrahydropalmitine was identified in chemical analysis. The analogous hepatotoxic constituent to Jin Bu Huan also contains Stephania sinica and various herbs. The two other herbal medicines contained no suspected hepatotoxins. The product lot of An Shu Ling was confiscated and a public health warning was issued. No additional cases associated with the use of this particular product were reported. Although Jin Bu Huan itself was banned from importation into the United States ${ }^{18}$ due to the known hepatotoxic risks, ${ }^{7,9}$ a shipment of An Shu Ling reportedly cleared US customs because the respective shipping invoice contained only the Chinese botanical name. ${ }^{18}$ See also Jin Bu Huan.

\section{Ba Jiao Lian}

After drinking infusions made with the TCM Ba Jiao Lian (Dysosma pleianthum) and consuming the recommended dose, five patients in Taiwan manifested abnormal liver function tests associated with nausea, vomiting, diarrhea, abdominal pain, thrombocytopenia, leucopenia, sensory ataxia, altered consciousness, and persistent peripheral tingling or numbness. ${ }^{19}$ In a recent report from Taiwan, 17 cases with poisoning by $\mathrm{Ba}$ Jiao Lian were published. ${ }^{20}$ Podophyllotoxin is one of the main ingredients of the Ba Jiao Lian root and is considered the toxic agent. ${ }^{19-21}$ However, the increase in the aminotransferases was small, with preference for the aspartate aminotransferase (AST) over the alanine aminotransferase (ALT). ${ }^{19,21}$ The increase of AST $^{19}$ could reflect either isolated damage of mitochondria around the hepatic central vein or some muscular damage ${ }^{21}$ because of the associated increase of creatine phosphokinase. ${ }^{19}$ These uncertainties do not allow for the classification of Ba Jiao Lian as a potentially hepatotoxic herb, and it is therefore not further considered within this review.

\section{Bai Fang}

A 54-year old male patient in the United States developed subtotal liver necrosis and survived following liver transplantation (LTX). ${ }^{22}$ He used Bai Fang as a herbal TCM for an unknown time and had acute hepatitis B virus (HBV) as a cofactor. Ingredients of Bai Fang include Angelica sinensis, Cyperus rotundus, Ginseng, Ligusticum wallichii, Paeonia alba, and Rehmannia glutinosa. The possible hepatotoxic herb and its suspected ingredient remain unknown, and the causality for Bai Fang is questionable because of the concomitant acute hepatitis B. No other cases were reported.

\section{Bai Xian Pi}

In four Korean patients, the use of the herb TCM Bai Xian Pi (Dictamnus dasycarpus) was hepatotoxic, when applied as a single herb. ${ }^{23}$ Similarly, it was hepatotoxic in three patients from the United Kingdom when it was coadministered with other herbs. ${ }^{24-26}$ Overall, fourteen patients from Korea developed acute toxic hepatitis due to Dictamnus dasycarpus, ${ }^{27}$ and two other Korean patients required a liver transplant due to acute liver failure. ${ }^{28}$ See also Chinese herbal mixtures. 
Teschke R.: Traditional Chinese medicine induced liver injury

Table 1. Required quality standards for assessing cases of suspected herbal Traditional Chinese Medicine (TCM) induced liver injury

Items with required quality specifications

Quality specification of herbal TCM products

- Good Agricultural Practices (GAPs)

- Good Manufacturing Practices (GMPs)

- Definition of plant family, subfamily, species, subspecies, and variety

- Definition of plant part

- Definition of solvents and solubilizers

- Lack of impurities, adulterants, and misidentifications

- Minimum batch to batch variability

- Minimum product to product variability

- Lack of variety to variety variability

TCM herbs and their use

- Brand name with details of ingredients, plant parts, batch number, and expiration date

- Identification as herbal TCM, herbal drug, or herbal supplement

- Herb as an ingredient of a polyherbal product or an undetermined herbal product

- Manufacturer with address

- Indication of herbal TCM use with dates of symptoms leading to herbal treatment

- Daily dose with details of the application form

- Exact date of herbal TCM start and herbal TCM end

Details and clinical course of patients

- Gender, age, body weight, height, and BMI

- Ethnicity and profession

- Past medical history regarding general diseases, specifically liver diseases

- Definition of risk factors such as age and alcohol

- Alcohol and drug use

- Statement regarding actual treatment including steroids or ursodesoxycholic acid

- Time frames of challenge, latency period, and dechallenge

- Accurate dates of emerging new symptoms after herbal TCM start in chronological order

- Accurate date of initially increased liver values

- ALT value initially including normal range

- ALT values during dechallenge at least on days 8,30 , and later

- ALT values during dechallenge to exclude a second peak

- ALT normalization with exact date and actual value

- ALP value initially including normal range

- ALP values during dechallenge at least on days 8,30 , and later

- ALP values during dechallenge to exclude a second peak

- ALP normalization with exact date and actual value

- AST value initially including normal range

- Laboratory criteria for definition of hepatotoxicity and its pattern

- Verification or exclusion of a temporal association

- Qualified data acquisition and documentation of complete data

- Transparent presentation of all data, not just superficial data

- Initial assessment of a temporal association, then causal relationship

Liver specific assessment of causality

- Liver specific causality assessment method

- Assessment method validated for hepatotoxicity

- Structured and quantitative method

- Use of the CIOMS scale

- Assessment by skilled hepatologist with clinical experience 
Teschke R.: Traditional Chinese medicine induced liver injury

Table 1. Continued

Items with required quality specifications

- Regulatory assessment with assistance of external experts

- High graded transparency of causality assessment results

- Presentation of the results item by item with individual scores

Exclusion of alternative diagnoses

- Assessment of preexisting and coexisting liver unrelated diseases

- Assessment of preexisting and coexisting liver diseases

- Consideration of the several hundred other possible liver diseases

- Providing details to exclude alternative diagnoses

- Assessment and exclusion of HAV, HBV, HCV, HEV, CMV, EBV, HSV, VZV

- Liver and biliary tract imaging, including color Doppler sonography of liver vessels

- Specific evaluation of alcoholic, cardiac, autoimmune, and genetic liver diseases

- Individual quantitative score of each alternative diagnosis

- Comedicated synthetic drugs, herbal drugs, herbal, and dietary supplements

- Individual quantitative score of each individual comedication

Reexposure tests and known hepatotoxicity of the herbal TCM

- Definition of and search for accidental, unintended reexposure

- Assessing and individual scoring of unintended reexposure

- Search for evidence of prior known hepatotoxicity of the suspected herbal TCM

- Assessing and individual scoring of known hepatotoxicity caused by the herbal TCM

Compiled for herbal hepatotoxicity by TCM and modified from previous reports. ${ }^{11,12,14}$ Abbreviations: ALP, alkaline phosphatase; ALT, alanine aminotransferase; AST aspartate aminotransferase; CMV, cytomegalovirus; EBV, Epstein Barr virus; HAV, hepatitis A virus; HBV, hepatitis B virus; HCV, hepatitis C virus; HEV, hepatitis E virus; HSV, herpes simplex virus; VZV, varicella zoster virus.

\section{Ban Tu Wan}

A middle-aged Asian female patient living in the United States acquired fulminant hepatic failure secondary to the use of the TCM Ban Tu Wan. ${ }^{29}$ Its ingredients were Angelica sinensis, Chaenomeles, Codonopsis pilosula, Notopterygium, Polygonum multiflorum, Rehmannia, and Schisandra. The patient was evaluated for a liver transplant but did not meet transplantation requirements because of septicemia, leading to a lethal outcome. ${ }^{29}$ Other hepatotoxicity cases caused by Ban Tu Wan have not been published. See also Ho Shou Wu, Polygonum multiflorum, Shen Min, and Shou Wu Pian.

\section{Bo He}

Two men, 45-years and 46-years, from Hong Kong with a chronic HBV infection took the TCM Bo He (Mentha haploca$(y x)$ in formulas that contained 11 elements with Bo He, shown to be hepatotoxic in the Chinese literature. ${ }^{30}$

\section{Bofu Tsu Sho San}

A 37-year old Japanese woman used the herbal TCM Bofu Tsu Sho San, a Japanese kampo medicine also called Bofu Tsu Sho San, and a diagnosis of herb induced liver injury was

Table 2. Prerequisites for positive reexposure tests in cases of suspected herbal Traditional Chinese Medicine (TCM) induced liver injury

\begin{tabular}{|c|c|c|c|c|}
\hline \multirow[b]{2}{*}{ Reexposure test result } & \multicolumn{2}{|c|}{ Hepatocellular type of injury } & \multicolumn{2}{|c|}{ Cholestatic ( \pm hepatocellular) type of injury } \\
\hline & ALTb & ALTr & ALPb & ALPr \\
\hline Positive & $<5 \mathrm{~N}$ & $\geqslant 2 \mathrm{ALTb}$ & $<2 \mathrm{~N}$ & $\geqslant 2 \mathrm{ALPb}$ \\
\hline Negative & $<5 N$ & $<2 \mathrm{ALTb}$ & $<2 \mathrm{~N}$ & $<2 \mathrm{ALPb}$ \\
\hline Negative & $\geqslant 5 N$ & $\geqslant 2 \mathrm{ALTb}$ & $\geqslant 2 \mathrm{~N}$ & $\geqslant 2 \mathrm{ALPb}$ \\
\hline Negative & $\geqslant 5 N$ & $<2 \mathrm{ALTb}$ & $\geqslant 2 \mathrm{~N}$ & $<2 \mathrm{ALPb}$ \\
\hline Negative & $\geqslant 5 N$ & n.a. & $\geqslant 2 \mathrm{~N}$ & n.a. \\
\hline Uninterpretable & $<5 N$ & n.a. & $<2 \mathrm{~N}$ & n.a. \\
\hline Uninterpretable & n.a. & n.a. & n.a. & n.a. \\
\hline
\end{tabular}

Modified and derived from previous reports. ${ }^{16,17}$ Required data for the hepatocellular type of liver injury are the ALT levels commonly just before reexposure, designed as baseline ALT or ALTb, and the ALT levels during reexposure, designed as ALTr and correlated to 2ALTb. Response to reexposure is positive, if both criteria are met: first, ALTb $<5 \mathrm{~N}$ with $\mathrm{N}$ as the upper limit of normal, and second ALTr $\geqslant 2 \mathrm{ALTb}$. Other variations lead to negative or uninterpretable test results. For the cholestatic ( \pm hepatocellular) type of liver injury, corresponding values of ALP are to be used rather than of ALT, but ALPb values focus on $2 \mathrm{~N}$ rather than on $5 \mathrm{~N}$ as for ALTb. Definitions of the hepatocellular and the cholestatic ( \pm hepatocellular) type of liver injury are provided previously. ${ }^{13-16}$ Abbreviations: ALP, Alkaline phosphatase; ALT, Alanine aminotransferase; n.a., not available. 
made. ${ }^{31}$ Bofu Tsu Sho San contains 16 herbs, Angelica, Atractylis, Cnidium, Gardenia, Ephedra, Forsythia, Glycyrrhhiza, Gypsum fibrosum, Ledebouriella, Mentha, Paeonia, Platycodon, Rheum, Schizonepeta, Scutellaria, and Zingiber, as well as Kadinum (talcum powder) and sodium sulfuricum. ${ }^{32}$ Several herbs are candidates for liver injury, including Ephedra that contains the hepatotoxic stimulant ephedrine. ${ }^{9,33}$ For Ephedra see also Ma Huang.

\section{Boh Gol Zhee}

Acute hepatitis was described after use of the TCM Boh Gol Zhee (syn. Bol Gol Zhee, Bu Gu Zhi, Bu Ku Zi, sheng Bu Gu Zhi, Sheng Po Gu Zhi) in two patients from Korea ${ }^{34,35}$ and in three patients from Hong Kong. ${ }^{36}$ Boh Gol Zhee represents not a herbal mixture but seeds of Psoralea corylifolia, and when used at high amounts psoralens are potentially hepatotoxic. ${ }^{34-36}$ Psoralens were hepatotoxic candidates in another patient who experienced severe hepatotoxicity with Indian Ayurvedic herbal products. ${ }^{37}$ These included Bakuchi tablets that contain extracts from Psoralea corylifolia leaves with psoralens for treatment of vitiligo.

\section{Bupleurum}

See Chai Hu.

\section{Camellia sinensis}

See Lu Cha.

\section{Chai Hu}

The risk of liver injury was increased in overall 61 Taiwanese patients with HBV infections treated with some products of TCM containing Chai Hu (Bupleurum falcatum). ${ }^{38}$ In particular, two products were involved, Xiao Chai Hu Tang with 19 patients and Long Dan Xie Gan Tang with 14 patients. In other individuals without HBV infections, various herbal TCM products containing Bupleurum may be hepatotoxic, see for instance Da Chai Hu Tang, ${ }^{39}$ Kamishoyosan, ${ }^{40}$ and a report referring to a herbal TCM mixture. ${ }^{25}$ See also Long Dan Xie Gan Tang and Xiao Chai Hu Tang.

\section{Chaso}

Six Japanese patients developed hepatic injury after using Chaso, a herbal TCM that promotes weight loss. ${ }^{41}$ This product contained Camellia sinensis (Green tea, syn. Lu Cha as TCM), the hepatotoxic Cassia tora (Senna), Crataegus, Chrysanthenum morifolium Ramat., Lotus, and Lycium barbarum. As an ingredient of the Chaso formula, Camellia sinensis extract is known to facilitate weight loss. Since the toxic property of Camellia sinensis extract was unknown in 2003 when Chaso hepatotoxicity was first described, it was not considered to be the hepatotoxic agent. ${ }^{41}$ Outcome was favorable in all patients, with only one patient requiring LTX. Chemical product analysis showed lack of fenfluramine and heavy metals, such as copper, lead, bismuth, cadmium, stibium, stanum, mercury, and chromium, but N-nitrosofenfluramine was found. $\mathrm{N}$-nitroso-fenfluramine was considered a possible but not yet proven culprit, ${ }^{41}$ since similar cases of hepatotoxicity by various other slimming aids in the United Kingdom, ${ }^{42}$ Hong Kong $^{43}$ and Japan ${ }^{44}$ including the
TCM herbal product Onshido, ${ }^{41}$ were reported. An additional 21 cases of Chaso-induced hepatotoxicity were reported to health officials in Japan and not further analyzed. ${ }^{41} \mathrm{~A}$ cautionary statement by the authors recommended further toxicological analyses to determine possible hepatotoxicity by $\mathrm{N}$-nitroso-fenfluramine, which was not established toxicologically or clinically until 2003. ${ }^{41}$ Toxicological evidence of its hepatotoxic property was not provided since 2003, and clinical evidence cannot be expected because it was removed from the market in 1997. The popular and widely used slimming aid fenfluramine was withdrawn from clinical use because of cardiac rather than hepatic complications, which remain unknown. ${ }^{41}$ Consequently, there is little toxicological and clinical evidence available regarding the hepatotoxicity of fenfluramine or $\mathrm{N}$-nitroso-fenfluramine. For more details and discussions see Lu Cha (Camellia sinensis) and Onshido.

\section{Chi R Yun}

Taiwanese patients who used the TCM Chi R Yun (Breynia officinalis) experienced hepatotoxicity. ${ }^{45-47}$ There was intentional and unintentional Chi R Yun overdose in two patients ${ }^{45}$ and acute poisonings in 19 patients. ${ }^{46,47}$ Because of their similarities, Breynia officinalis was mistaken for another plant, the TCM Yi Yi Qui (Securinega suffruticosa). ${ }^{46,47}$

\section{Chinese herbal mixtures}

Patients of this section used an unnamed, unclassified herbal mixture of TCM. Additionally, in some of these cases, only individual herbs had been declared by name. Since the herbal mixtures have all herbs presented as ingredients, these mixtures could not be added to an existing named herbal product group.

Herbal hepatotoxicity was published for a heterogeneous group of herbal mixtures of TCM, ${ }^{24-26,48-51}$ primarily from the United Kingdom. ${ }^{24-26,48-50}$ In three cases, hepatotoxicity was described following herbal TCM use, but firm details concerning the applied herbs were missing. ${ }^{48-50}$ More information was provided by other reports. ${ }^{24-26}$ One treatment consisted of Dictamnus dasycarpus (syn. Bai Xian Pi), Gentiana scabra, Hedyotis diffusa, Paeonia suffructicosa, Paris polyphylla, Rehmannia glutinosa, Smilax glabra, and Sophora subprostrata. ${ }^{25}$ Another patient used Angelica sinensis, Bupleurum chinese, Dictamnus dasycarpus, Paeonia suffructiosa, Philodendron chinese, Saposhnikovia divaricata, Shisandra chinesis, Shizonepeta tenuifolia, and Tribulus terrestris. ${ }^{25} \mathrm{~A}$ third patient with a fatal clinical course used a mixture consisting of Cocculus trilobus, Dictamnus dasycarpus, Eurysolen gracilis, Glycyrrhiza, Lophatherum, Paeonia, Potentilla, and Rehmannia glutinosa. ${ }^{24}$ Considering these three cases from two reports, ${ }^{24,25}$ it is possible that either Dictamnus dasycarpus or Paeonia species could be the toxic herb. ${ }^{25}$ Four Korean patients with toxic liver injury used Dictamnus dasycarpus as a single herb. ${ }^{23}$ In addition, analysis of a herbal remedy taken by another patient with fulminant liver failure and unsuccessful LTX confirmed the presence of Dictamnus dasycarpus. These cases support an etiological role of this herb in TCM hepatoxicity. ${ }^{26}$

The herbal mixture of TCM used by a patient in Canada led to acute liver failure and successful LTX in the United States. ${ }^{51}$ This mixture consisted of twelve herbs, including Alisma plantago aquatica, Artemisia capillaris, Bupleurum, Chrysanthemum morifolium, Circuma, Gardenia jasminoidis, 
Teschke R.: Traditional Chinese medicine induced liver injury

Gentiana scabra, Glycyrrhiza, Magnolia, Paeonia, Plantago asiatica, and Saussurea lappa. The toxic culprit remains unknown.

\section{Chinese skullcap}

See Huang Qin.

\section{Chuan Lian Zi}

A 45-year old male patient with chronic HBV infection from Hong Kong was treated with the TCM Chuan Lian Zi (Melia toosendan) and experienced herbal hepatotoxicity. ${ }^{30}$

\section{Ci Wu Jia}

Two Korean patients consumed the herbal TCM Ci Wu Jia (Acanthopanax senticosus), developed acute toxic hepatitis with acute liver failure, and required LTX. ${ }^{25}$

\section{Da Chai Hu Tang}

In a Japanese patient, autoimmune hepatitis was triggered by the use of the TCM Da Chai Hu Tang (syn. Dai Saiko To, TJ-8), a mixture of aqueous extracts from seven plants, Bupleurum falcatum, Ginseng, Glycyrrhiza glabra, Pinellia, Scutellaria, Zingiber officinale, and Zizyphus jujuba. ${ }^{39}$ The specific culprit remained unknown. Da Chai Hu Tang contains the same components as the potentially hepatotoxic TCM Xiao Chai Hu Tang (syn. Sho Saiko To Syo Saiko To, Syo Xiao Hu Tang, TJ9) but in different proportions. ${ }^{39,52}$ See also Bupleurum and Xiao Chai Hu Tang.

\section{Da Huang}

A 45-year old man from Hong Kong with chronic HBV infection used the herbal TCM Da Huang (Rhubarb, Rheum palmatum) and died from acute liver and organ failure due to herbal hepatotoxicity. ${ }^{30}$

\section{Dai Saiko To}

See Dai Chai Hu Tang.

\section{Dan Zhi Xiao Yao San}

See Kamishoyosan.

\section{Dictamnus dasycarpus}

See Bai Xian Pi.

\section{Gan Cao}

A 46-year old man from Hong Kong with a chronic HBV infection took the TCM Gan Cao (syn. Glycyrrhiza uralensis, Liquorice, Gan Cao Zhi, Shen Nong Ben Cao Jing, Zhi Gan Cao) in formulas. These contained 11 elements, and Gan Cao was the likely toxic agent for the observed hepatotoxicity. ${ }^{30}$ Recovery was complete after discontinuation of Gan Cao.

\section{Ge Gen}

The two 57- and 58-years old women from Korea ingested juice of the herbal TCM Ge Gen (Pueraria lobata, syn. Arrowroot) and developed symptomatic toxic hepatitis. ${ }^{53}$ Clinical symptoms and laboratory findings rapidly improved following cessation of Ge Gen and supportive care.

\section{Glycyrrhiza uralensis}

See Gan Cao.

\section{Ho Shou Wu}

A 54-year old Korean woman consumed Polygonum multiflorum as the TCM Ho Shou Wu (syn. He Shou Wu, Shou Wu Wan, Fo Ti) and experienced toxic hepatitis. ${ }^{54}$ Hepatotoxicity in a 33-year old woman from Hong Kong with a chronic HBV infection was assumed to be due to Ho Shou Wu as well. However, other medications also included the hepatotoxic Jue Ming Zi (Cassia obtusifolia tora, Senna) and 10 additional, unidentified herbal items. ${ }^{30}$

\section{Huang Qin}

Nineteen Japanese patients developed liver injury after the use of the herbal TCM Huang Qin (Scutellaria baicalensis, syn. Chinese skullcap), which is a herbal mixture called Ogon in Kampo medicine of Japan. ${ }^{55}$ Hepatotoxicity was described in four patients from the United States who used Huang Qin in a dietary supplement which also contained black catechu (Acacia catechu), glucosamine, chondroitin, and hyaluronic acid. ${ }^{56-58}$ Acacia catechu was used as one of several Indian Ayurvedic herbs in a patient with severe hepatotoxicity and is thereby a possible culprit. ${ }^{37}$ However, the herbal extract of Chinese skullcap is the more likely cause of the reported hepatotoxicity. ${ }^{56-58}$ There are some hundred species of skullcap (Scutellaria), including Scutellaria lateriflora, that have potential hepatotoxic risks, but often information regarding respective species was missing. ${ }^{9}$

\section{Hwang Geun Cho}

A 37-year old Korean male patient consumed the herbal TCM Hwang Geun Cho (Corydalis speciosa) and was diagnosed with acute herbal hepatotoxicity. ${ }^{59}$ Symptoms disappeared and laboratory values gradually returned to near normal values following cessation and supportive management.

\section{Ji Gu Cao}

A 38-year old man from Hong Kong with chronic hepatitis B took the herbal TCM Ji Guo Cao (syn. Abrus cantoniensis, Ji Gu Cao Wan) and was diagnosed with herb induced liver injury, possibly caused by contaminated hepatotoxic seeds. ${ }^{30}$

\section{Ji Xue Cao}

Three women aged 61, 52, and 49 years from Argentina ingested the herbal TCM Ji Xue Cao (Centella asiatica, syn.Gotu Kola) and developed herbal hepatotoxicity by Centella asiatica. ${ }^{60}$ Outcomes were favorable after discontinuation of the medication and ursodeoxycholic acid therapy. 


\section{Jia Wei Xiao Yao San}

See Kamishoyosan.

Jiguja

A 3.5 year old boy from Korea consumed tea prepared from the herbal TCM Jiguja (Hovenia dulcis), resulting in the development of toxic hepatitis. ${ }^{61}$ Because acute liver failure emerged, the boy was transferred to another hospital for further evaluation and eventually LTX. In addition, two other adults from Korea developed toxic hepatitis after ingesting Hovenia dulcis, ${ }^{27,28,61}$ and one of these patients required LTX. ${ }^{28}$

\section{Jin Bu Huan}

Hepatotoxicity associated with the herbal TCM Jin Bu Huan, syn. An Shu Ling, ${ }^{18}$ was reported from Hong Kong, ${ }^{62}$ in eleven patients from the United States, ${ }^{18,63-65}$ one patient from Canada, ${ }^{63}$ and one patient from Italy. ${ }^{66}$ L-tetrahydropalmitate is the active ingredient of Jin Bu Huan and the presumed causative agent for hepatotoxicity. The herbal medication usually contains only Lycopodium serratum, or rarely several unrelated herbal species, including Corydalis species, Panax ginseng, Pseudo ginseng, or two species of Stephania. ${ }^{18,63-67}$

\section{Jing Tian San Qi}

Prior to 2008, there were 41 reported cases from China of hepatic sinusoidal obstruction syndrome (HSOS), formerly called hepatic veno-occlusive disease (HVOD), attributed to the herbal TCM Jing Tian San Qi (Sedum aizoon, syn. Stonecrop). ${ }^{68}$ However, causal attribution to Sedum aizoon was in retrospect incorrect. Sedum aizoon lacks pyrrolizidine alkaloids (PAs), and when administered to experimental animals, HSOS did not emerge. ${ }^{69}$ This suggested that a herb containing PAs was likely responsible for the reported cases. ${ }^{68}$ Consistent with this, in another hepatotoxicity case from Hong Kong, HSOS was initially ascribed to Sedum aizoon but was later determined to be caused by the herbal TCM Shan Chi (Gynura segetum). ${ }^{69}$ The appearance of Sedum aizoon is similar to Gynura segetum but can be differentiated by an expert eye. ${ }^{69}$ Comparative studies with both herbs provided clear supportive evidence for Gynura segetum as the culprit for additional cases of HSOS over Sedum aizoon. Respective studies showed in mice that the PAs containing Gynura segetum but not the PAs lacking Sedum aizoon produced experimental HSOS as assessed by liver histology. ${ }^{69}$ In an earlier experimental study, a model of the hepatic veno-occlusive disease was established by PAs derived from a herb described erronously as Sedum aizoon, ${ }^{70}$ which again does not contain PAs. ${ }^{69,71,72}$ This suggested that the described experimental model ${ }^{70}$ was due to the action of a herb containing PAs, most likely Gynura segetum, 69,71-73 rather than to PAs lacking Sedum aizoon..$^{71}$ Other authentication problems of Gynura segetum had to be resolved in relation to the TCM Mao Guo Tian Jie Cai (Heliotropium lasiocarpum), another herb that also contains PAs. ${ }^{74-76}$ HSOS cases had been initially attributed to Gynura segetum, ${ }^{74,75}$ but this causal attribution was in retrospect incorrect since Heliotropium lasiocarpum was determined as culprit. ${ }^{76}$ Overall, careful analyses finally led to a clear picture of HSOS by Gynura segetum. ${ }^{77,78}$ Taken together, there is little evidence for the hepatotoxic potential of Jing Tian San Qi. Therefore, the herbal TCM Sedum aizoon will not be further considered for hepatotoxicity.

\section{Jue Ming $\mathbf{Z i}$}

A 33-year old woman from Hong Kong with a chronic HBV infection was treated with the herbal TCM Jue Ming Zi (syn. Cassia obtusifolia, Senna obtusifolia, Cao Jue Ming) and experienced liver injury. ${ }^{30}$

\section{Kamishoyosan}

In one single Japanese woman, liver injury was reported following the use Kamishoyosan, a traditional Japanese herbal drug (Kampo medicine) and synonym to the TCM Jia Wei Xiao Yao San, Dan Zhi Xiao Yao San, or TJ-24. ${ }^{40}$ Kamishoyosan is a herbal mixture and contains several components, including Angelica sinensis, Atractylodes racea, Bupleurum falcatum, Gardenia, Glycyrrhiza glabra, Mentha haplocalyx, Moutan, Paeonia alba, Sclerotium Poriae Cocos, and Zingiber officinale, as described in the case report ${ }^{40}$ or as assessed by an internet search for a refined botanical description of the herbal components. Detecting the causative agents was difficult, but Scutellaria was definitively excluded. ${ }^{54,79}$ There is some uncertainty regarding the Mentha species, declared as Mentha herb in the case report ${ }^{40}$ and as mentha (pennyroyal) subsequently. ${ }^{79}$ An additional internet search to further determine the Mentha species commonly used in Kamishoyosan found Mentha haplocalyx Briq or Mentha arvensis var. piperascens Malinvaud (Japanese field mint) as the most probable component.

\section{Kudzu}

Six patients from Korea consumed the herbal TCM Kudzu (Pueraria thunbergiana) and were diagnozed with acute toxic hepatitis. 27

\section{Liquorice}

See Gan Cao.

\section{Long Dan Xie Gan Tang}

Overall, fourteen Taiwanese patients with HBV infection were found to be at higher risk for hepatotoxicity when treated with the TCM Long Dan Xie Gan Tang (syn. Long Dan Xie Gan Wan). ${ }^{38}$ This herbal mixture contains Acebia, Alisma, Angelica sinensis, Bupleurum, Gardenia, Gentiana, Glycyrrhiza, Plantago, Rehmannia, and Scutellaria. A similar increase in risk was observed in another patient group treated with the TCM Xiao Chai Hu Tang, which also contains Bupleurum among other herbs. See also Bupleurum and Xiao Chai Hu Tang.

\section{Long Dan Xie Gan Wan}

See Long Dan Xie Gan Tang.

\section{Lu Cha}

Lu Cha (Camellia sinensis, green tea) is a TCM plant and one of several herbal ingredients in the two herbal mixtures Chaso 
and Onshido. These mixtures were marketed as weight loss aids by Chinese pharmaceutical companies and found to be hepatotoxic, as described in $2003 .{ }^{41} \mathrm{~N}$-nitroso-fenfluramine but not green tea was discussed as the possible but unproven hepatotoxic ingredient for these herbal mixtures. However, this case series did not prove that $\mathrm{N}$-nitrosofenfluramine was the toxic agent. ${ }^{41}$ Whether Camellia sinesis may have contributed to the observed hepatotoxicity is unclear, because information on the amounts of green tea in these two products was not provided. At least as an extract, Camellia sinensis is a potent weight loss aid with potentially hepatotoxic effects, as thoroughly discussed first in 2004 ${ }^{80-82}$ and in subsequent years.9,83-88 Therefore, hepatotoxicity of green tea as extracts was not yet clearly established in 2003 when the respective case reports were published. ${ }^{41}$

Green tea is one of the most popular beverages, as are black tea and coffee. There is no question that the conventional use of these beverages including green tea does not harm the liver. In the past, however, weight loss aids were supplemented by green tea concentrated as extracts, and these carried the risk of liver injury. ${ }^{9,80-88}$ According to the manufacturers, the weight loss aids Chaso and Onshido contained green tea and other herbs. ${ }^{41}$ Presumably, green tea was included as extracts to enhance weight loss, although the extract form was not specifically mentioned by the manufacturers. The producers did not mention that the synthetic adulterant $\mathrm{N}$-nitroso-fenfluramine was also an ingredient in the two products. This adulterant was later identified by chemical analyses, but evidence of hepatotoxicity was not presented and evaluation by further studies was recommended. ${ }^{41}$ The most likely candidate for the liver injury was green tea, if it was supplied in the extract form. For details see also Chaso and Onshido.

\section{Ma Huang}

Six patients originating from the United States experienced acute hepatitis associated with the use of the herbal TCM Ma Huang and its ingredients of Ephedra species. ${ }^{9,22,33,89-91}$ Out of these six cases, one patient also coadministered kava, one also had disulfiram, and one had a chronic HBV infection. ${ }^{22}$ Two patients developed acute liver failure, ${ }^{22,90}$ and one of them required $L T X .^{22}$ In another patient from the United Kingdom, acute liver failure emerged and LTX was necessary. ${ }^{92}$ Ma Huang is also one of the ingredients of ProLean $\AA,{ }^{9}$ a potential hepatotoxic herbal mixture. ${ }^{93}$ For Ephedra, see also Bofu Tsu Sho San.

\section{Mao Guo Tian Jie Cai}

In four patients from Hong Kong, HSOS developed following the use of the PAs containing herbal TCM Mao Guo Tian Jie Cai (Heliotropium lasiocarpum). ${ }^{76}$ It was initially mistaken as the PAs containing herbal TCM Gynura segetum. ${ }^{73-75}$ Outcome was deleterious for one of the four patients. ${ }^{76}$

\section{Onshido}

Six Japanese patients experienced hepatic injury due to the use of the weight loss aid Onshido, a TCM herbal mixture. ${ }^{41}$ This herbal product contained Aloe, Camellia sinensis, Crataegus, Gynostemma pentaphyllum makino, and Raphanus. Outcome was favorable in all patients except for one with a lethal clinical course. Chemical product analysis of Onshido showed lack of fenfluramine and heavy metals such as copper, lead, bismuth, cadmium, stibium, stanum, mercury, and chromium but the presence of $\mathrm{N}$-nitroso-fenfluramine as a possible but ultimately unproven hepatotoxic agent. N-nitroso-fenfluramine was also considered the possible culprit in additional cases of hepatotoxicity by various other slimming aids in the United Kingdom, ${ }^{42}$ Hong Kong, ${ }^{43}$ including the TCM product Chaso in Japan. ${ }^{41}$ Additional 135 Onshido-induced cases of hepatotoxicity were reported to health officials in Japan but not further analyzed. ${ }^{41}$ The hepatotoxic properties of Camellia sinensis extracts were discovered in 2004, ${ }^{9}$ and its role in Camellia sinensis induced hepatotoxicity was not evaluated in $2003 .{ }^{41}$ For additional details and discussions see also Chaso and Lu Cha (Camellia sinensis).

\section{Phyllanthus urinaria}

\section{See Zhen Chu Cao.}

\section{Polygonum multiflorum}

Polygonum multiflorum is a member of the family Polygonaceae, genus Fallopia. Either alone or in combination with other herbs and vitamins, it is a constituent of various potentially hepatotoxic herbal TCM products. ${ }^{28-30,54,94-98}$ Among these are Ban Tu Wan, ${ }^{29}$ Ho Wu Shou, ${ }^{30,54}$ Shen Min, ${ }^{95}$ and Shou Wu Pian. ${ }^{96-103}$ Occasionally, Polygonum multiflorum containing herbal TCM products such as Ho Shou Wu, Shen Min, Shou Wu Pian, and Zhi Shou Wu are considered interchangeable terms. ${ }^{94}$ However, ingredients may vary from product to product, requiring specific and qualifying product names. The mechanism of hepatotoxicity of Polygonum multiflorum is not known and disputed, ${ }^{94-96,99-}$ 101 although the injury is usually attributed to the anthraquinones such as chrysophanol, emodin, and rhein, which are major constituents in Polygonum multiflorum. ${ }^{94}$ In a single report, however, the major compound identified in the recovered tablets was a stilbene glycoside, tetrahydroxystilbene-glucopyranoside. ${ }^{94,96}$ LTX was necessary in three patients from Korea after using Polygonum multiflorum. ${ }^{28}$ For details see Ban Tu Wan, Chinese herbal mixtures, Ho Wu Shou, Shen Min and Shou Wu Pian.

\section{Rhen Shen}

Six patients originating from Korea used the herbal TCM Rhen Shen (Panax ginseng, Ren Seng) and developed acute toxic hepatitis. $^{27}$

\section{Sairei To}

Two Japanese men consumed the kampo medicine Sarei To (syn. Chai Ling Tang), which is a blend of two TCMs, Xiao Chai Hu Tang and Wu Ling San Wan, and experienced herbal hepatotoxicity. ${ }^{104,105}$ Among the Sairei To ingredients are Alisma, Atractylis, Bupleurum, Cinnamomum, Ginseng, Glycyrrhiza, Pinellia, Polyporus, Poria, Scutellaria, Zingiber, and Zizyphus. Several possible culprits are under consideration, including Pinellia ternate, ${ }^{104}$ and other components of Sairei To. ${ }^{105}$ 


\section{Shan Chi}

In two Chinese women, 51 and 39 years old, HSOS emerged, which was induced by PAs of the herbal TCM Shan Chi Gynura segetum (syn. Ju San Qi, Ju Shan Qi, Ju Ye San Qi, San Qi Cao). ${ }^{73}$ One of these two patients required a LTX. Other cases of HSOS by Gynura segetum were reported from China, $59,60,77,78$ with a lethal outcome in one patient. ${ }^{59}$ In a 54-year old woman with HSOS from Hong Kong, PAs derived from Gynura segetum rather than the herbal TCM Jing Tian San Qi (Sedum aizoon) devoid of PAs were the likely hepatotoxic agents. ${ }^{69}$

Additional six cases were earlier suspected, ${ }^{74,75}$ but in at least four cases the culprit was the PAs containing herb Heliotropium lasiocarpum rather than Gynura segetum. ${ }^{76} \mathrm{An}$ additional four patients experienced HSOS by Gynura segetum, one with a lethal course. ${ }^{71}$ Correspondingly, at least 52 HSOS cases have been attributed to Gynura segetum until $2011{ }^{69}$ and 116 cases until $2012 .^{71}$

The clinical features have now been clearly described, establishing Gynura segetum but not Jing Tian San Qi (Sedum aizoon) as the cause of HSOS. ${ }^{69,71,72}$ The diagnosis was ascertained in a 54-year old female patient with HSOS by thorough investigations of the patient herself and by animal studies. ${ }^{69}$ Her clinical diagnosis of HSOS was firmly established by meeting the modified Seattle criteria, characterized by hyperbilirubinemia, hepatomegaly, and weight gain due to fluid accumulation. Liver histology confirmed the diagnosis of HSOS. Pyrrole-protein adducts as biomarkers and pyrrole-GSH conjugates detected in her blood using the new method ultra performance liquid chromatography-mass spectrometry

(UPLC-MS) analysis. Since the ingested herb was unknown, the cultivated herb from the patient's home was collected and authenticated as the TCM herb Gynura segetum. Together with the authenticated TCM herb Sedum aizoon cultivated and collected from another Chinese area, various comparative studies in animals were made. All of these studies confirmed that the observed HSOS arose from the consumption of PAs containing Gynura segetum, an erroneous substitute of the non PAs containing Sedum aizoon. ${ }^{69}$ The blood test of pyrrole-protein adducts using UPLC-MS analysis was employed as a biological biomarker in subsequent patients. ${ }^{71}$

\section{Shen Min}

A 28-year old woman from the United States developed acute hepatitis following the use of the herbal TCM Shen Min. ${ }^{95}$ The product label for this Shen Min product had a list of components that included plants and vitamins. Polygonum multiflorum is one of the main components of Shen Min, and the respective content was described as Shen Min 12: 1 standardized extract (Polygonum multiflorum) $450 \mathrm{mg}$ per serving and as He Shou Wu powder $870 \mathrm{mg}$ per serving. Polygonum multiflorum, however, was not specified here. Other declared contents of the used Shen Min product were vitamin $A$, vitamin $B_{6}$, biotin, niacin, pantothenic acid, soy isoflavones, black cohosh, horse chestnut, hydrolyzed collagen, silica from plant sources, ginkgo biloba, uva ursi, Burdock, Cayenne pepper, and Piper nigrum. See also Ho Shou Wu, Polygonum multiflorum, and Shou Wu Pian.

\section{Shou Wu Pian}

As described in 1996, a 31-year old pregnant Chinese woman from Hong Kong developed acute hepatitis after consumption of the TCM Shou Wu Pian, with Polygonum multiflorum as the main component. ${ }^{99}$ Subsequently, similar case reports related to Shou Wu Pian followed from Australia, ${ }^{100}$ Italy, ${ }^{98,101}$ the Netherlands (a 5-year old girl), ${ }^{96}$ the United States, ${ }^{102}$ Japan, ${ }^{103}$ and Korea. ${ }^{97}$ Shou Wu Pian is a herbal mixture with a wide variability of its ingredients, and details are rarely mentioned. ${ }^{94,97,103}$ For example, according to the information via the internet, one of the numerous possible formula compositions could be: Achyranthes bidentata, Cuscuta chinensis, Eclipta prostrata, Ligustrum lucidum, Lonicera japonica, Morus alba, Polygonum multiflorum, Psoralea corylifolia, Rehmannia glutinosa, Rosa laevigata, Sesemum indicum, and Siegesbeckia orientalis. This composition varies substantially from the one of Shen Min, ${ }^{95}$ which also contains Polygonum multiflorum and is discussed above. See also Ho Shou Wu, Polygonum multiflorum, and Shen Min.

\section{Syo Saiko To}

See Xiao Chai Hu Tang.

\section{TJ-8}

See Da Chai Hu Tang.

TJ-9

See Xiao Chai Hu Tang.

TJ-24

See Kamishoyosan.

\section{White flood}

A 23-year old man from the United States experienced hepatotoxicity following use of the commercial product White flood, which contained the herbal TCM Wu Zhu Yu (Evodia rutaecarpa, club moss) and the herbal TCM Qian Ceng Ta (Huperzia serrata). ${ }^{106}$ Other ingredients included acesulfame potassium, beet root, caffein, calcium silicate, carnitine tartrate, Carno-Syn $₫$ beta-alanine, citrulline, cocoa bean, cryptoxanthin, folic acid, gamma-aminobutyric acid (GABA), glucuronolactone, selenium, L-norvaline, L-tyrosine, lutein, malic acid, ornithine, potassium gluconate, sucralose, sugar cane, vinpocetine (from Vinca plant), watermelon flavor, and zeaxanthin. After discontinuing use of the product, the outcome was favorable.

\section{Xiao Chai Hu Tang}

The treatment with the herbal TCM Xiao Chai Hu Tang (syn. Sho Saiko To, Syo Saiko To, Syo Xiao Hu Tang, TJ-9) resulted in liver injury in four Japanese patients with increased liver values prior to treatment. ${ }^{107}$ For 19 Taiwan patients with HBV infection, treatment with Xiao Chai Hu Tang was associated with an increased risk for liver injury. ${ }^{38}$ One additional patient from Taiwan had the same response to Xiao Chai Hu Tang following cholecystectomy. ${ }^{108}$ Xiao Chai Hu Tang is a mixture of several herbs, including Bupleurum falcatum, Ginseng, 
Glycyrrhiza glabra, Pinellia tuber, Scutellaria baicalensis, Zingiber officinale, and Zizyphus jujuba. Therefore, its composition is the same as the TCM Da Chai Hu Tang (syn. Dai Saiko To, TJ-8), but in different proportions. ${ }^{39,52}$ See also Bupleurum, Da Chai Hu Tang, and Long Dan Xie Gan Tang.

\section{Yin Chen Hao}

In seven patients from Korea, the use of the herbal TCM Yin Chen Hao (Artemisia capillaris) resulted in the development of acute toxic hepatitis. ${ }^{27}$ One additional Korean patient did require $L T X .^{28}$

\section{Zexie}

A 59-year old man from Hong Kong with chronic hepatitis B and associated $\mathrm{HBeAg}$-positive liver cirrhosis was treated for cramps with a herbal TCM formula consisting of eleven different herbal elements, including the hepatotoxic Zexie (Alisma orientalis). ${ }^{30}$ He died from complications due to a severe course of herbal hepatotoxicity.

\section{Zhen Chu Cao}

A 37-year old man from Hong Kong with a chronic hepatitis $B$ had been taking the TCM Zhen Chu Cao (syn. Phyllanthus urinaria) and experienced herbal hepatotoxicity due to Zhen Chu Cao. ${ }^{30}$ After cessation of the toxic herbal product, there was a full recovery.

\section{Zhi Gan Cao}

\section{See Gan Cao.}

\section{Clinical and regulatory considerations}

The present study is a very limited analysis of herbal TCM hepatotoxicity based on some hundred cases published in 91 reports. Most patients made a full recovery upon cessation of the herbal TCM product, ${ }^{18-108}$ but some developed acute liver failure. $24,28,29,30,41,51$ In these publications, individual herbs and herbal mixtures suggested to be hepatotoxic included An Shu Ling, Bai Fang, Bai Xian Pi, Ban Tu Wan, Bo He, Bofu Tsu Sho San, Boh Gol Zhee, Chai Hu, Chaso, Chi R Yun, Chuan Lian Zi, Ci Wu Jia, Da Chai Hu Tang, Da Huang, Gan Cao, Ge Gen, Ho Shou Wu, Huang Qin, Hwang Geun Cho, Ji Gu Cao, Ji Xue Cao, Jiguja, Jin Bu Huan, Jue Ming Zi, Kamishoyosan, Kudzu, Long Dan Xie Gan Tang, Lu Cha, Ma Huang, Mao Guo Tian Jie Cai, Onshido, Polygonum multiflorum, Ren Shen, Sairei To, Shan Chi, Shen Min, Shou Wu Pian, White flood, Xiao Chai Hu Tang, Yin Chen Hao, Zexie, Zhen Chu Cao, and various unclassified Chinese herbal mixtures. The reporting physicians likely assumed for each case a clear causal association between the use of the herbal TCM product and hepatotoxicity. However, this assumption is often based merely on a temporal association and requires further rigorous evaluation.

A good approach with some limitations for the establishment of causality for a given herb or herbal mixture in hepatotoxicity is to assess reported positive reexposure test results. They are obtained through unintentional readministration, although this is commonly observed in only a few selected cases. ${ }^{16,17}$ In the past, this assessment has been done for 34 cases of suspected herbal hepatotoxicity, including 14 cases due to herbal TCM, ${ }^{17}$ applying established criteria for a positive reexposure test (Table 2 ). Among the now assessed 25 patients of suspected herbal hepatotoxicity of TCM with reported positive reexposure test results, criteria based evaluation confirmed a positive reexposure test result in 14 cases, whereas the results were negative in four cases or uninterpretable in seven cases (Table 3). Accordingly, positive reexposure test results were obtained for Chinese herbal mixtures (cases 2 and 3), Hwang Geun Cho (case 6), Ji Xue Cao (case 7), Jin Bu Huan (cases 9 and 10), Lu Cha (cases 13-15), Polygonum multiflorum (case 20), Shou Wu Pian (case 21), and Xiao Chai Hu Tang (cases 23-25) (Table 3 ), confirming the hepatotoxic risk of these products. ${ }^{17}$

The liver specific CIOMS scale for causality assessment is applicable to all cases of suspected herbal TCM hepatotoxicity. ${ }^{14,15,27,28,30,53,69,71,97,109,110}$ This scale was rarely used in the cases of the present evaluation, ${ }^{18-108}$ although CIOMS data were provided for all 7, 25, and 27 TCM cases in three studies. ${ }^{30,97,110}$ In the course of causality assessment, highly probable or probable causality levels were obtained for various types of TCM formulas, ${ }^{30}$ Bai Xian $\mathrm{Pi}^{27,28}$ Chinese herbal mixtures, ${ }^{17} \mathrm{Ci} \mathrm{Wu} \mathrm{Jia},{ }^{28} \mathrm{Gan} \mathrm{Coa},{ }^{30} \mathrm{Ge}$ Gen, ${ }^{53} \mathrm{Ho}$ Shou Wu, ${ }^{54}$ Juguja, ${ }^{28} \mathrm{Ji}$ Xue Cao, ${ }^{60} \mathrm{Jin}$ Bu Huan, ${ }^{17} \mathrm{Kudzu},{ }^{27}$ Ling Yang Qing Fei Keli, ${ }^{30}$ Lu Cha, ${ }^{82,83}$ Polygonum multiflorum, ${ }^{17,30}$ Rhen Shen, ${ }^{27}$ Shan Chi, ${ }^{69,71}$ Shen Min, ${ }^{95}$ Syo Saiko To, ${ }^{17}$ Yin Chen Hao, ${ }^{27,28}$ and Zexie. ${ }^{30}$ Clinical assessment was partly difficult because data were often incomplete in many cases regarding indication for treatment, daily dose, quantitative composition of herbal mixtures, duration of treatment, exclusion of alternative causes, and clinical course. ${ }^{18-108}$ These shortcomings are also common to cases of herb induced liver injury, which are unrelated to $\mathrm{TCM}^{7,12,14-17,111}$ and to drug induced liver injury. ${ }^{112}$

Some common TCM herbs and herbal products with potential hepatotoxicity were not discussed or specifically referenced above as additional cases since they were listed without further details. ${ }^{62}$ Among these are Cang $\mathrm{Er} \mathrm{Zi}$ (Xanthium sibiricum), Chuan Lian Zi (Melia toosendan), Hu Bohe You (Mentha pulegium, Pennyroyal oil), Hu Zhang (Polygonum cuspidatum), Huang Yao Zi (Dioscorea bulbifera), Ji Ji (Chloranthus serratus), Jin Bu Huan (Lycopodium serratum and other herbs), Lei Gong Teng (Tripterygium wilfordii Hook), Ma Huang (Ephedra sinica), Qian Li Guang (Senecio scandens), Shi Can (Teucrium chamaedrys, Germander), Shi Liu Pi (Pericarpium granati), Tian Hua Fen (Trichosanthes kirilowii), Wu Bei Zi (Galla chinensis), Xi Shu (Camptotheca acuminata), and Xiao Chai Hu Tang (Bupleurum falcatum, Scutellaria baicalensis, and other herbs). ${ }^{62}$ Additional lists refer to 24 cases of liver damage by Polygonum multiflorum, ${ }^{113}$ two cases of markedly elevated liver enzymes with the herbal TCM Bo Ye Qing Niu Dan (Tinospora crispa), ${ }^{114}$ and to a single case of liver injury with verified causality by the CIOMS scale attributed to the herbal TCM Du Huo (Angelica archangelica). ${ }^{115}$

Problematic for human use is the possible lack of quality control and authentication of herbal products (Table 1$)^{12}$ as well as adulteration and contamination with dust, pollens, insects, rodents, parasites, microbes, fungi, mold, toxins, and pesticides. ${ }^{6}$ For herbal TCM products, specific problems have been linked to mislabeling on the package insert ${ }^{3,63}$ including the wrong herbs, ${ }^{46,47}$ insufficient sample amounts, ${ }^{116}$ adulteration with undeclared synthetic drugs, ${ }^{3,6,10,62}$ contamination by hepatotoxic seeds ${ }^{30}$ and heavy metals such as 
Teschke R.: Traditional Chinese medicine induced liver injury

Table 3. Analysis of reported positive reexposure test results in cases of suspected herbal Traditional Chinese Medicine (TCM) induced liver injury

Case Reexposure tests in cases of suspected herbal TCM induced liver injury

1. 28 -year old UK woman: ${ }^{24}$ Chinese herbal mixture with 8 different herbs for 3-5 months. Jaundice. ALT value not available. Reexposure: episode of hepatitis reported without liver values, acute liver failure, died despite emergency LTX. Both ALTb and ALTr not available $\rightarrow$ uninterpretable reexposure.

2. -39-year old UK woman: ${ }^{25}$ Chinese herbal mixture with 8 different herbs for 2 months. Short history of anorexia, nausea, fatigue, dark urine, yellow sclerae, jaundice. ALT $2440 \mathrm{U} / \mathrm{L}$ (normal 0-30) with R 68.3, ALT returned to normal after cessation. Reexposure after 6 weeks: ALT $1314 \mathrm{U} / \mathrm{L}$. ALTb $<5 \mathrm{~N}$ and ALTr $\geqslant 2$ ALTb $\rightarrow$ positive reexposure.

3. 9-year old UK girl: ${ }^{48}$ Unclassified Chinese herbal medicine for 6 months. Nausea, anorexia, central abdominal pain, jaundice, pale stool for the past 4-21 days. ALT $1950 \mathrm{U} / \mathrm{L}$ (normal $<45$ ) with R 13.1, ALT returned to $50 \mathrm{U} / \mathrm{L}$ after cessation. Intentional reexposure: ALT $315 \mathrm{U} / \mathrm{L}$. ALTb $<5 \mathrm{~N}$ and $\mathrm{ALTr} \geqslant 2 \mathrm{ALTb} \rightarrow$ positive reexposure.

\section{Ho Shou Wu}

4. $\quad$ 54-year old Korean woman: ${ }^{54}$ Unknown dose of Ho Shou Wu containing Polygonum multiflorum for 1 month. Diagnosis of toxic hepatitis. Cessation of Ho Shou Wu improved her condition. Reexposure started immediately after discharge with aggravation of liver values. English abstract and Korean article $\rightarrow$ uninterpretable reexposure.

\section{Huan Qin}

5. $\quad$ 78-year old US woman: ${ }^{57}$ Move Free Advanced $\AA 2$ tablets/d containing Huan Qin (Scutellaria baicalensis, Chinese skullcap), black catechu, glucosamine, and chondroitin for 3 weeks. Jaundice. ALT $1626 \mathrm{U} / \mathrm{L}$ (normal $<60$ ) with R 10.2, ALT $678 \mathrm{U} / \mathrm{L}$ two weeks after cessation. Reexposure: ALT $1206 \mathrm{U} / \mathrm{L}$. ALTb $\geqslant 5 \mathrm{~N}$ and ALTr $<2 \mathrm{ALTb} \rightarrow$ negative reexposure.

\section{Hwang Geun Cho}

6. -37-year old male patient from Korea: ${ }^{59}$ Hwang Geun Cho containing Corydalis speciosa. Jaundice. ALT 531 U/L with subsequent decline after cessation of the herb down to $146 \mathrm{U} / \mathrm{L}$. Unintentional reexposure two months after discharge: ALT $381 \mathrm{U} / \mathrm{L}$. ALTb $<5 \mathrm{~N}$ and ALTr $\geqslant 2 \mathrm{ALTb} \rightarrow$ positive reexposure.

\section{Ji Xue Cao}

7. 61 -year old Argentinian woman: ${ }^{60} \mathrm{Ji}$ Xue Cao (Centella asiatica, syn.Gotu Kola) tablets for 30 days. Jaundice. ALT $1193 \mathrm{U} / \mathrm{L}$ and two months after cessation $18 \mathrm{U} / \mathrm{L}$. Unintentional reexposure seven months later : ALT 481 U/L. ALTb $<5 \mathrm{~N}$ and $\mathrm{ALTr} \geqslant 2 \mathrm{ALTb} \rightarrow$ positive reexposure.

8. $\quad$ 52-year old female patient from Argentina: ${ }^{60} \mathrm{Ji}$ Xue Coa (Centella asiatica) for six months. Jaundice. Not further quantified elevated hepatic enzymes at beginning and after cessation. Unintentional reexposure one year later : ALT 1694 U/L. ALTb not availabe $\rightarrow$ uninterpretable reexposure.

\section{Jin Bu Huan}

9. $\quad 66$-year old US woman: ${ }^{63}$ Jin Bu Huan 2 tablets at night 2 to 3 times a week for 12 weeks. Fever, nausea, fatigue for the past 5 weeks. ALT $782 \mathrm{U} / \mathrm{L}$ (normal <35) with R 18.7, ALT declined to $47 \mathrm{U} / \mathrm{L}$ following cessation. Reexposure: ALT $941 \mathrm{U} / \mathrm{L}$. ALTb $<5 \mathrm{~N}$ and $\mathrm{ALTr} \geqslant 2 \mathrm{ALTb} \rightarrow$ positive reexposure.

10. -46-year old US man: ${ }^{63}$ Jin Bu Huan 3 tablets 3 times a week intermittently for 6 months. Fever, headaches, fatigue, tender hepatomegaly. ALT $394 \mathrm{U} / \mathrm{L}$ (normal < 35) 2 weeks after cessation with R 24.2, ALT subsequently $48 \mathrm{U} / \mathrm{L}$. Reexposure: ALT $100 \mathrm{U} / \mathrm{L}$. ALTb $<5 \mathrm{~N}$ and $\mathrm{ALTr} \geqslant 2 \mathrm{ALTb} \rightarrow$ positive reexposure.

11. $\quad 50$-year old US woman: ${ }^{64}$ Jin Bu Huan 2-3 tablets daily or intermittently for around 24 days. Fever. ALT 830 U/L and $330 \mathrm{U} / \mathrm{L}$ after cessation. Reexposure: ALT $540 \mathrm{U} / \mathrm{L}$. ALTb $\geqslant 5 \mathrm{~N}$ and ALTr $<2 \mathrm{ALTb} \rightarrow$ negative reexposure.

12. 70 -year old US woman: ${ }^{64}$ Jin Bu Huan 3 to 4 tablets at night 3 to 5 times a week for 31 days. Chills and fever 12 days after start of use, subsequently low-grade fever, malaise. ALT $408 \mathrm{U} / \mathrm{L}$ initially, $263 \mathrm{U} / \mathrm{L}$ after 2- week cessation, $67 \mathrm{U} / \mathrm{L}$ after 6-week cessation. Reexposure after 1 month: ALT $77 \mathrm{U} / \mathrm{L}$. ALTb $<5 \mathrm{~N}$ but ALTr $<2 \mathrm{ALTb} \rightarrow$ negative reexposure.

\section{Lu Cha}

13. 56 -year old French woman: ${ }^{82}$ Mincifit $114 \mathrm{ml} / \mathrm{d}$ containing green tea (Camellia sinensis, TCM Lu Cha) and Cassia sp. extracts for 15 days. Jaundice. ALT 54N with R 54.0, ALT normalization 2 months after cessation. Reexposure 5 years later with Dynasvelte forte $\mathbb{R} 8-12 \mathrm{~g} / \mathrm{d}$ for 21 days (Green tea, Coffea Arabica, and chromium): ALT 99N. ALTb $<5 \mathrm{~N}$ and $\mathrm{ALTr} \geqslant 2 \mathrm{ALTb} \rightarrow$ positive reexposure.

14. 45 -year old Spanish man: ${ }^{83}$ Green tea infusion ( 6 cups/day) over 4 months. Asthenia and jaundice of 10 days duration prior to cessation. ALT $1613 \mathrm{U} / \mathrm{L}$ (normal < 40) with R 14.3, ALT normalized within 2 months of cessation. Reexposure 6 weeks later: ALT $1460 \mathrm{U} / \mathrm{L}$ after 1 month of reuse. ALTb $<5 \mathrm{~N}$ and ALTr $\geqslant 2 A L T b \rightarrow$ positive reexposure. 
Teschke R.: Traditional Chinese medicine induced liver injury

Table 3. Continued

\begin{tabular}{|c|c|}
\hline Case & Reexposure tests in cases of suspected herbal TCM induced liver injury \\
\hline 15. & $\begin{array}{l}\text { - 37-year old Hispanic woman from the US: }{ }^{84} \text { Green tea-containing product with various other herbal extracts for } 4 \\
\text { months. Jaundice. ALT } 1788 \mathrm{U} / \mathrm{L}(\text { normal }<40 \text { ) with } \mathrm{R} 21.7, \mathrm{ALT} 92 \mathrm{U} / \mathrm{L} \text { after withdrawal. Reexposure one year later } \\
\text { for one month: ALT } 1131 \mathrm{U} / \mathrm{L} \text {. ALTb }<5 \mathrm{~N} \text { and } \mathrm{ALTr} \geqslant 2 \mathrm{ALTb} \rightarrow \text { positive reexposure. }\end{array}$ \\
\hline 16. & $\begin{array}{l}\text { - } 23 \text {-year old Spanish woman: }{ }^{85} \text { Green tea (Camellia sinensis) for } 21 \text { days. Jaundice after } 19 \text { days. ALT } 56.9 \mathrm{~N} \text { with } \mathrm{R} \\
34.7, \mathrm{ALT} 0.35 \mathrm{~N} 3 \text { months after withdrawal. Reexposure: ALT values not available. ALTb }<5 \mathrm{~N} \text { but ALTr not available } \\
\rightarrow \text { uninterpretable reexposure. }\end{array}$ \\
\hline 17. & $\begin{array}{l}\text { - 26-year old Spanish woman: }{ }^{85} \text { Green tea for } 121 \text { days. Jaundice. ALT } 32.1 \mathrm{~N} \text { with } \mathrm{R} 42.2 \text {, ALT dechallenge values } \\
\text { not available. Reexposure: ALT values not available. Both ALTb and ALTr not available } \rightarrow \text { uninterpretable reexposure. }\end{array}$ \\
\hline 18. & $\begin{array}{l}\text { - } 38 \text {-year old French woman: }{ }^{86} \text { Green tea ( } 6 \text { caps Tealine } \AA / d \text {, containing also white and red tea) for } 20 \text { days. } \\
\text { Symptoms not reported. ALT values not available. Reexposure: ALT value not available. Both ALTb and ALTr not } \\
\text { available } \rightarrow \text { uninterpretable reexposure. }\end{array}$ \\
\hline
\end{tabular}

\section{Ma Huang}

19. 33 -year old US woman: ${ }^{89}$ Unknown daily dose of Ma Huang for around 4 weeks. Nausea, vomiting, abdominal discomfort after use for several days, jaundice under continuing Ma Huang use for another 3 weeks. ALT 832 U/L (normal <65) with R 9.8. ALT dechallenge values not available. Intentional reexposure with a single dose 1 week after discharge: ALT $1586 \mathrm{U} / \mathrm{L}$. Both ALTb and ALTr not available $\rightarrow$ uninterpretable reexposure.

\section{Polygonum multiflorum}

20. $\quad$ 61-year old Korean man: ${ }^{97}$ Unknown dose of Polygonum multiflorum Thunb for 1 day. Myalgia. ALT 818 U/L with R 21.6, $180 \mathrm{U} / \mathrm{L}$ after 9 days of cessation and $\mathrm{ALTb}<5 \mathrm{~N}$ as likely assumed. Reexposure after 11.5 months with a single dose of $P$. multiflorum Thunb: ALT $1520 \mathrm{U} / \mathrm{L}$. ALTb $<5 \mathrm{~N}$ and ALTr $\geqslant 2 \mathrm{ALTb} \rightarrow$ positive reexposure.

\section{Shou Wu Pian}

21. - 5-year old Netherland girl: ${ }^{96}$ Shou Wu Pian (3 tablets daily) for 4 months. Jaundice. ALT 1543 U/L (normal $<39$ U/ L), 5 weeks after cessation 50 U/L. Reexposure with 2 tablets Shou Wu Pian daily for 1 month: ALT 1277 U/L. ALTb < $5 \mathrm{~N}$ and $\mathrm{ALTr} \geqslant 2 \mathrm{ALTb} \rightarrow$ positive reexposure.

\section{Xiao Chai Hu Tang}

22. - 51-year old Japanese woman: ${ }^{107} 7.5 \mathrm{~g}$ of Xia Chai Hu Tang daily for 7 weeks. Jaundice, with preexisting mild elevations of aminotransferases. ALT $855 \mathrm{U} / \mathrm{L}$ (normal < 35) with R 35.9, ALT decrease to $139 \mathrm{U} / \mathrm{L}$ upon cessation. Reexposure: ALT $186 \mathrm{U} / \mathrm{L}$. ALTb $<5 \mathrm{~N}$ but ALTr $<2$ ALTb $\rightarrow$ negative reexposure.

23. 52 -year old Japanese woman: ${ }^{107}$ Xia Chai Hu Tang $7.5 \mathrm{~g}$ daily for 6 weeks. Jaundice, preexistent ALT activity of $180 \mathrm{U} / \mathrm{L}$ (normal < 35). ALT $600 \mathrm{U} / \mathrm{L}$, near normal 2.5 months after withdrawal. Reexposure: ALT $162 \mathrm{U} / \mathrm{L}$. ALTb < $5 \mathrm{~N}$ and $\mathrm{ALTr} \geqslant 2 \mathrm{ALTb} \rightarrow$ positive reexposure.

24. -58-year old Japanese woman: ${ }^{107}$ Xia Chai Hu Tang $7.5 \mathrm{~g}$ daily for 3 months. Symptoms not reported. ALT 246 U/L (normal < 35) with R 5.0, ALT fell to near normal after 2 months of withdrawal. Intentional 7-day reexposure: ALT $265 \mathrm{U} / \mathrm{L}$. ALTb $<5 \mathrm{~N}$ and ALTr $\geqslant 2 \mathrm{ALT} \rightarrow$ positive reexposure.

25. - 42-year old Japanese woman: ${ }^{107}$ Xia Chai Hu Tang $7.5 \mathrm{~g}$ daily for an unspecified time period for hepatitis A infection. Symptoms not specified, ALT $2165 \mathrm{U} / \mathrm{L}$ (normal $<35$ ) initially dropped with treatment to $42 \mathrm{U} / \mathrm{L}$ and increased 3 weeks after initiation of treatment. ALT $1335 \mathrm{U} / \mathrm{L}$ with normalization within 2 months after withdrawal. Intentional 2- day reexposure: ALT $195 \mathrm{U} / \mathrm{L} A L T b<5 \mathrm{~N}$ and $\mathrm{ALTr} \geqslant 2 \mathrm{ALTb} \rightarrow$ positive reexposure.

Compilation of some clinical details and laboratory values for assessment of reported positive reexposure test results in 25 cases with suspected herbal hepatotoxicity by TCM products. ${ }^{24,25,48,54,57,59,60,63,64,82-86,89,96,97,107}$ Data are derived from a previous report, which may provide additional details. ${ }^{17}$ Unless otherwise stated, reexposure was commonly unintentional. Criteria for a positive reexposure test result were used as described in Table 2, restricted to criteria provided for the hepatocellular type of liver injury. Accordingly, essential data are the ALT levels at baseline before reexposure (ALTb) and the ALT levels during reexposure (ALTr). Response to reexposure is positive if $\mathrm{ALTr} \geqslant 2 \mathrm{ALTb}$ and $\mathrm{ALTb}<5 \mathrm{~N}$, with $\mathrm{N}$ as the upper limit of the normal value. Other combinations lead to negative or uninterpretable results. Serum enzyme activities were provided in $\mathrm{U} / \mathrm{L}$ or multiples of $\mathrm{N}$. Details for calculation of the $\mathrm{R}$ value were presented previously. ${ }^{17}$ Abbreviation: ALT, alanine aminotransferase; AST, aspartate aminotranferase; N, upper limit of normal; R, ratio; TCM, Traditional Chinese Medicine.

arsenic, mercury, and lead. ${ }^{6,116}$ These shortcomings are well recognized ${ }^{1-12,14,116}$ and require efforts by manufacturers and regulatory agencies (Table 1 ). ${ }^{117}$

Of additional concern is the potential hepatotoxicity of non-herbal TCM elements. ${ }^{10,27,28,30,62,118-122}$ They are commonly used in connection with herbal TCM products, ${ }^{10,30}$ and even named as such. ${ }^{10}$ Known or potentially hepatotoxic nonherbal TCM elements are Bai Hua She (venom of the Chinese viper Agkistrodon acutus), ${ }^{30}$ Jiang Can (dried larvae of Bombyx Batryticatus, infected by Batrytis bassiana), ${ }^{30}$ Ling Yang Qing Fei (antelope horn), ${ }^{30}$ Liyu Danzhi (carp juice), ${ }^{118}$
Quan Xie (dry polypides of the Scorpio Buthus martensii), ${ }^{30}$ Sang Hwang (Phellinus linteus, mushroom), 27,28 Song Rong (Agaricus blazei, Himematsutake as Japanese Kampo Medicine, mushroom), ${ }^{119}$ Wu Gong (dried polypites of the centipede Scolopendra subspinipes mutilans), ${ }^{30}$ Wu Shao She (syn. Wu Xiao She, Sheng Wu Shao She, parts of the snake Zaocys dhumnades), ${ }^{30}$ and Yu Dan (fish gallbladder). ${ }^{120-122}$

Finally and most importantly, the use of a few TCM products caused serious hepatotoxicity in some susceptible patients resulting in a severe clinical course with 
additional risk for acute liver failure, LTX requirement, and lethality. 22,24,28-30,41,51 Between 1992 and 2008, in Seoul (Korea) alone 24 patients underwent LTX due to acute toxic hepatitis caused by herbal medicine and preparations. ${ }^{28}$ This is unacceptable because the benefits of herbal TCM products are at present only rarely and inadequately documented. ${ }^{4,5}$ For the sake of the consumer, a stringent evaluation of the risk/benefit ratio based on results of multicenter, randomized, double-blind, placebo-controlled clinical trials should be the primary goal. ${ }^{4}$ The future practice of pharmacovigilance and risk control of TCM herbs and drugs in China are promising. ${ }^{117}$

\section{Conclusions}

In a few susceptible individuals, some commonly used herbal TCM products may rarely cause hepatotoxicity with the risk of a severe clinical course with acute liver failure, the requirement for LTX, and potential lethality. This necessitates a stringent evaluation of the risk/benefit ratio for any prospective treatment with herbal TCM products, based on results of multicenter, randomized, double-blind, placebo-controlled clinical trials.

\section{Conflict of interest}

None

\section{Author contributions}

Writing the manuscript (RT).

\section{References}

[1] http://nccam.nih.gov/health/whatiscam/chinesemed.htm, accessed 10 January 2014

[2] Tang JL, Liu BY, Ma KW. Traditional Chinese medicine. Lancet 2008;372: 1938-1940. doi: 10.1016/S0140-6736(08)61354-9.

[3] Ernst E. Adulteration of Chinese herbal medicines with synthetic drugs: a systematic review. J Intern Med 2002;252:107-113. doi: 10.1046/j.13652796.2002.00999.x.

[4] Ernst E. Methodological aspects of Traditional Chinese Medicine (TCM). Ann Acad Med Singapore 2006;35:773-774.

[5] Tang JL, Zhan SY, Ernst E. Review of randomised controlled clinical trials of traditional Chinese medicine. BMJ 1999;319:160-161. doi: 10.1136/ bmj.319.7203.160.

[6] Posadzki P, Watson L, Ernst E. Contamination and adulteration of herbal medicinal products (HMPs): an overview of systematic reviews. Eur J Clin Pharmacol 2013;69:295-307.

[7] Teschke R, Schwarzenboeck A, Eickhoff A, Frenzel C, Wolff A, Schulze J. Clinical and causality assessment in herbal hepatotoxicity. Expert Opin Drug Saf 2013;12:339-366. doi: 10.1517/14740338.2013.774371.

[8] http://livertox.nih.gov/ChineseAndOtherAsianHerbalMedicines.htm, accessed 10 January 2014

[9] Teschke R, Wolff A, Frenzel C, Schulze J, Eickhoff A. Herbal hepatotoxicity: A tabular compilation of reported cases. Liver Int 2012;32:1543-1556. doi: 10.1111/j.1478-3231.2012.02864.x.

[10] Shaw D. Toxicological risks of Chinese herbs. Planta Med 2010;76:20122018. doi: 10.1055/s-0030-1250533.

[11] Teschke R, Lebot V. Proposal for a Kava Quality Standardization Code. Food Chem Toxicol 2011;49:2503-2516. doi: 10.1016/j.fct.2011.06.075.

[12] Teschke R, Frenzel C, Glass X, Schulze J, Eickhoff A. Herbal hepatotoxicity: A critical review. Br J Clin Pharmacol 2013;75:630-636.

[13] Danan G, Bénichou C. Causality assessment of adverse reactions to drugs I. A novel method based on the conclusions of international consensus meetings: application to drug-induced liver injuries. J Clin Epidemiol 1993; 46:1323-1330. doi: 10.1016/0895-4356(93)90101-6.
[14] Teschke R, Frenzel C, Schulze J, Eickhoff A. Herbal hepatotoxicity: challenges and pitfalls of causality assessment methods. World J Gastroenterol 2013; 19:2864-2882.

[15] Teschke R, Eickhoff A, Schulze J. Drug and herb induced liver injury in clinical and translational hepatology: Causality assessment methods, quo vadis? J Clin Translat Hepatol2013;1:59-74. doi: 10.14218/JCTH.2013. D002X

[16] Teschke R, Frenzel C, Schulze J, Schwarzenboeck A, Eickhoff A. Herbalife hepatotoxicity: Evaluation of cases with positive reexposure tests. World J Hepatol 2013;5:353-363.

[17] Teschke R, Genthner A, Wolff A, Frenzel C, Schulze J, Eickhoff A. Herbal hepatotoxicity: Analysis of cases with initially reported positive reexposure tests. Dig Liver Dis 2014;46:264-269. doi: 10.1016/j.dld.2013.10.020.

[18] Haller CA, Dyer JE, Ko R, Olson KR. Making a diagnosis of herbal-related toxic hepatitis. West J Med 2002:176:39-44.

[19] Kao WF, Hung DZ, Tsai WJ, Lin KP, Deng JF. Podophyllotoxin intoxication: toxic effect of Bajiaolian in herbal therapeutics. Hum Exp Toxicol 1992;11: 480-487. doi: 10.1177/096032719201100607.

[20] Chou SL, Chou MY, Kao WF, Yen DH, Yen LY, Huang CI, et al. Bajiaolian poisoning - a poisoning with high misdiagnostic rate. Am J Emerg Med 2010;28:85-89.

[21] http://livertox.nih.gov/BaJiaoLian.htm, accessed 10 January 2014.

[22] Estes JD, Stolpman D, Olyaei A, Corless CL, Ham JM, Schwartz JM, et al. High prevalence of potentially hepatotoxic herbal supplement use in patients with fulminant hepatic failure. Arch Surg 2003;138:852-858. doi: 10.1001/archsurg.138.8.852.

[23] Jang JS, Seo EG, Han C, Chae HB, Kim SJ, Lee JD, et al. Four cases of toxic liver injury associated with Dictamnus dasycarpus. Korean J Hepatol 2008 14:206-212.

[24] Perharic-Walton L, Murray V. Toxicity of traditional Chinese herbal remedies. Lancet 1992;340:674. doi: 10.1016/0140-6736(92)92209-X

[25] Kane JA, Kane SP, Jain S. Hepatitis induced by traditional Chinese herbs: possible toxic components. Gut 1995;36:146-147. doi: 10.1136/ gut.36.1.146.

[26] Vautier G, Spiller RC. Safety of complementary medicines should be monitored. BMJ 1995;311:633. doi: 10.1136/bmj.311.7005.633b.

[27] Kang SH, Kim JI, Jeong KH, Ko KH, Ko PG, Hwang SW, et al. Clinical characteristics of 159 cases of acute toxic hepatitis. Korean J Hepatol 2008; 14:483-492.

[28] Sohn CH, Cha MI, Oh BJ, Yeo WH, Lee JH, Kim W, et al. Liver transplantation for acute toxic hepatitis due to herbal medicines and preparations. J Korean Soc Clin Toxicol 2008;6:110-116.

[29] Cortez E, Boulger C, Bernard A. Ban Tu Wan hepatotoxicity. BM] Case Rep 2012; 2012. doi: 10.1136/bcr-2012-006438.

[30] Yuen MF, Tam S, Fung J, Wong DK, Wong BC, Lai CL. Traditional Chinese Medicine causing hepatotoxicity in patients with chronic hepatitis B infection: a 1-year prospective study. Aliment Pharmacol Ther 2006;24: 1179-1186. doi: 10.1111/j.1365-2036.2006.03111.x.

[31] Motoyama H, Enomoto M, Yasuda T, Fujii H, Kobayashi S, Iwai S, et al. Drug-induced liver injury caused by a herbal medicine, bofu-tsu-sho-san. Nihon Shokakibyo Gakkai Zasshi 2008;105:1234-1239.

[32] Sakamoto S, Takeshita S, Sassa S, Suzuki S, Ishikawa Y, Kudo H. Effects of colestimide and/or Bofu-tsusho-san on plasma and liver lipids in mice fed a high-fat diet. In vivo 2005;19:1029-1034.

[33] http://livertox.nih.gov/Ephedra.htm, accessed 10 January 2014

[34] Hwang SH, Park JA, Jang YS, Lee KM, Lee DS, Ahn BM, et al. Case of acute cholestatic hepatitis caused by the seeds of Psoralea-corylifolia. Korean J Hepatol 2001;7:341-344.

[35] Nam SW, Baek JT, Lee DS, Kang SB, Ahn BM, Chung KW. A case of acute cholestatic hepatitis associated with the seeds of Psoralea corylifolia (BohGol-Zhee). Clin Toxicol (Phila) 2005;43:589-591. doi: 10.1081/CLT200068863.

[36] Cheung WI, Tse ML, Ngan T, Lin J, Lee WK, Poon WT, et al. Liver injury associated with the use of Fructus Psoraleae (Bol-gol-zhee or Bu-gu-zhi) and its related propriety medicine. Clin Toxicol (Phila) 2009;47:683-685. doi: $10.1080 / 15563650903059136$

[37] Teschke R, Bahre R. Severe hepatotoxicity by Indian Ayurvedic herbal products: A structured causality assessment. Ann Hepatol 2009;8:258266.

[38] Lee CH, Wang JD, Chen PC. Risk of liver injury associated with Chinese herbal products containing Radix bupleuri in 639,779 patients with hepatitis B virus infection. PLoS One 2011;6:e16064. doi: 10.1371/journal.pone. 0016064

[39] Kamiyama T, Nouchi T, Kojima S, Murata N, Ikeda T, Sato C. Autoimmune hepatitis triggered by administration of an herbal medicine. Am J Gastroenterol 1997;92:703-704.

[40] Inoue H, Yamazaki S, Shimizu M, Uozki H, Goto T, Ohnishi S, et al. Liver injury induced by the Japanese herbal drug kamishoyosan. Gastroenterol Hepatol (N Y) 2011:7:692-695 
[41] Adachi M, Saito $H$, Kobayashi $H$, Horie $Y$, Kato $S$, Yoshioka M, et al. Hepatic injury in 12 patients taking the herbal loss aids Chaso and Onshido. Ann Intern Med 2003;139:488-492. doi: 10.7326/0003-4819-139-6200309160-00012.

[42] Lai V, Smith A, Thorburn D, Raman VS. Severe hepatic injury and adulterated Chinese medicines. BMJ 2006;332:304-305. doi: 10.1136/ bmj.332.7536.304-b.

[43] Yuen YP, Lai CK, Poon WT, Ng SW, Chan AY, Mak TW. Adulteration of overthe-counter slimming products with pharmaceutical analogues - an emerging threat. Hong Kong Med J 2007;13:216-220.

[44] Kanda T, Yokosuka O, Tada M, Kurihara T, Yoshida S, Suzuki Y, et al. Nnitroso-fenfluramine hepatotoxicity resembling chronic hepatitis. J Gastroenterol Hepatol 2003;18:999-1000. doi: 10.1046/j.14401746.2003.03074.x

[45] Lin TJ, Tsai MS, Chiou NM, Deng JF, Chiu NY. Hepatotoxicity caused by Breynia officinalis. Vet Hum Toxicol 2002;44:87-88.

[46] Lin TJ, Su CC, Lan CK, Jiang DD, Tsai JL, Tsai MS. Acute poisonings with Breynia officinalis - an outbreak of hepatotoxicity. J Toxicol Clin Toxicol 2003;41: 591-594. doi: 10.1081/CLT-120023760.

[47] http://livertox.nih.gov/ChiRYun.htm, accessed 10 January 2014.

[48] Allen BR, Parkinson R, Hollman A, Jones R, Harper JI, Davies EG,et al. Chinese herbs for eczema. Lancet 1990;336:177. doi: 10.1016/01406736(90)91696-8.

[49] Graham-Brown R. Toxicity of Chinese herbal remedies. Lancet 1992;340:673. Reply: Rustin M, Atherton D. Lancet 1992;340:673-674. doi: 10.1016/0140-6736(92)92208-W.

[50] Sanders D, Kennedy N, McKendrick MW. Monitoring the safety of herbal remedies: Herbal remedies have a heterogeneous nature. Br Med J 1995; 311:1569. doi: 10.1136/bmj.311.7019.1569a.

[51] Yoshida EM, McLean CA, Cheng ES, Blanc PD, Somberg KA, Ferrell LD, et al. Chinese herbal medicine, fulminant hepatitis, and liver transplantation. Am J Gastroenterol 1996;91:2647-2648.

[52] http://livertox.nih.gov/ShoSaikoTo_DaiSaikoTo.htm, accessed 10 January 2014.

[53] Kim SY, Yim HJ, Ahn JH, Kim JH, Kim JN, Yoon I, et al. Two cases of toxic hepatitis caused by arrowroot juice. Korean J Hepatol 2009;15:504-509.

[54] Bae SH, Kim DH, Bae YS, Lee KJ, Kim DW, Yoon JB, et al. Toxic hepatitis associated with Polygoni multiflori. Korean J Hepatol 2010;16:182-186.

[55] Gono Y, Odaguchi H, Hayasaki T, Suzuki K, Oikawa T, Muranushi A, et al. Clinical analysis of cases with drug-induced liver injury for Kampo medicine. Kampo Med 2010;61:828-833. doi: 10.3937/kampomed.61.828.

[56] Linnebur SA, Rapacchietta OC, Vejar M. Hepatotoxicity associated with chinese skullcap contained in Move Free Advanced dietary supplement: two case reports and review of the literature. Pharmacotherapy 2010;30:258262.

[57] Yang L, Aronsohn A, Hart J, Jensen D. Herbal hepatotoxicity from Chinese skullcap: A case report. World J Hepatol 2012;4:231-233.

[58] Dhanasekaran R, Owens V, Sanchez W. Chinese skullcap in Move Free arthritis supplement causes drug induced liver injury and pulmonary infiltrates. Case Reports Hepatol 2013; Article ID 965092. doi: org/ $10.1155 / 2013 / 965092$

[59] Kang HS, Choi HS, Yun TJ, Lee KG, Seo YS, Yeon JE, et al. A case of acute cholestatic hepatitis induced by Corydalis speciosa Max. Korean J Hepatol 2009; 15:517-523.

[60] Jorge OA, Jorge AD. Hepatotoxicity associated with the ingestion of Centella asiatica. Rev Esp Enferm Dig 2005;97:115-124. doi: 10.4321/S113001082005000200006.

[61] Kim Y], Ryu SL, Shim JW, Kim DS, Shim JY, Park MS, et al. A pediatric case of toxic hepatitis induced by Hovenia dulcis. Pediatr Gastroenterol Hepatol Nutr 2012;15:111-116. doi: 10.5223/pghn.2012.15.2.111.

[62] Chau TN. Drug-induced liver injury: an update. Medical Bulletin 2008;13: 23-26.

[63] Woolf GM, Petrovic LM, Rojter SE, Wainwright S, Villamil FG, Katkov WN, et al. Acute hepatitis associated with the Chinese herbal product Jin $\mathrm{Bu}$ Huan. Ann Intern Med 1994;121:729-735. doi: 10.7326/0003-4819-12110-199411150-00001.

[64] Horowitz RS, Feldhaus K, Dart RC, Stermitz FR, Beck J]. The clinical spectrum of Jin Bu Huan toxicity. Arch Intern Med 1996;156:899-903. doi: 10.1001/archinte.1996.00440080101012.

[65] Divinsky M. Case report: Jin Bu Huan - not so benign herbal medicine. Can Fam Physician 2002;48:1640-1642.

[66] Picciotti A, Campo N, Brizzolara R, Giusto R, Guido G, Sinelli N, et al. Chronic hepatitis induced by Jin Bu Huan. J Hepatol 1998;28:165-167. doi: 10.1016/S0168-8278(98)80217-1.

[67] http://livertox.nih.gov/JinBuHuan.htm, accessed 10 January 2014.

[68] Wu GL, Yu GY, Chen J. Clinical analysis of hepatic veno-occlusive disease induced by Sedum aizoon. Zhongguo Zhong Yao Za Zhi 2008; 33: 24022404.
[69] Lin G, Wang JY, Li N, Li M, Gao H, Ji Y, et al. Hepatic sinusoidal obstruction syndrome associated with consumption of Gynura segetum. J Hepato 2011;54:666-673. doi: 10.1016/j.jhep.2010.07.031.

[70] Gao XS, Xiao SS, He JF. Analysis of alkaloids in Sedum aizoon and establishment of hepatic veno-occlusive model in mice. Chin J Integr Trad West Med Dig 2006;14:311-313.

[71] Gao H, Li N, Wang JY, Zhang SC, Lin G. Definitive diagnosis of hepatic sinusoidal obstruction syndrome induced by pyrrolizidine alkaloids. J Dig Dis 2012;13:33-39.

[72] Wang JY, Gao H. Tusanqi and hepatic sinusoidal obstruction syndrome. J Dig Dis 2014;15:105-107.

[73] Dai HF, Gao Y, Yang M, Yu CH, Gu ZY, Chen WX. Hepatic veno-occlusive disease induced by Gymura segetum: report of two cases. Hepatobiliary Pancreat Dis Int 2006;5:406-408.

[74] Kumana CR, Ng M, Lin HJ, Ko W, Wu PC, Todd D. Herbal tea induced hepatic veno-occlusive disease: quantification of toxic alkaloid exposure in adults. Gut 1985;26:101-104. doi: 10.1136/gut.26.1.101.

[75] Kumana CR, Ng M, Lin HJ, Ko W, Wu PC, Todd D. Hepatic veno-occlusive disease due to toxic alkaloid in herbal tea. Lancet $1983 ; 2: 1360-1361$. doi: $10.1016 /$ S0140-6736(83)91112-1.

[76] Culvenor CC, Edgar JA, Smith LW, Kumana CR, Lin HJ. Heliotropium lasiocarpum Fisch and Mey identified as cause of veno-occlusive disease due to herbal tea. Lancet 1986;1:978. doi: 10.1016/S01406736(86)91084-6.

[77] Chen MY, Cai JT, Du Q. Hepatic veno-occlusive disease associated with the use of Gynura segetum. Eur J Intern Med 2007;18:609.

[78] Li C, Liang XS, Li CZ. Sinusoidal obstruction syndrome associated with the ingestion of gynura root. Clin Toxicol (Phila) 2010;48:962-964. doi: $10.3109 / 15563650.2010 .527851$.

[79] Fenkel JM, Navarro VJ. Herbal and dietary supplement-induced liver injury. Gastroenterol Hepatol 2011;7:695-696.

[80] Duenas Sadornil C, Fabregas Piugtio S, Durandez R. Hepatotoxicity due to Camelia sinensis. Med Clin (Barc) 2004;122:677-678. doi: 10.1157/ 13061393.

[81] Garcia-Moran S, Saez-Royuela F, Gento E, Lopez Morante A, Arias L. Acute hepatitis associated with Camellia tea and Orthosiphon stamineus ingestion. Gastroenterol Hepatol 2004;27:559-560. doi: 10.1016/S02105705(03)70527-5.

[82] Peyrin-Biroulet $L$, Petitpain N, Kalt $P$, Ancel $D$, Petit-Laurent $F$, Trechot $P$, et al. Probable hepatotoxicity from epigallocatecol gallate used for phytotherapy. Gastroenterol Clin Biol 2004;28;404-406. doi: 10.1016/ S0399-8320(04)94944-5.

[83] Jimenez-Saenz M, Martinez-Sanchez Mdel C. Acute hepatitis associated with the use of green tea infusions. J Hepatol 2006;44:616-617. doi 10.1016/j.jhep.2005.11.041.

[84] Bonkovsky HL. Hepatotoxicity associated with supplements containing Chinese green tea (Camellia sinensis). Ann Intern Med 2006:144:68-71. doi: 10.7326/0003-4819-144-1-200601030-00020.

[85] García-Cortés M, Borraz Y, Lucena MI, Peláez G, Salmerón J, Diago M, et al. Liver injury induced by "natural remedies": an analysis of cases submitted to the Spanish Liver Toxicity Registry. Rev Esp Enferm Dig 2008;100:688695.

[86] Sarma DN, Barrett ML, Chavez ML, Gardiner P, Ko R, Mahady GB, et al. Safety of green tea extract: a systematic review by the US Pharmacopeia. Drug Saf 2008;31:469-484. doi: 10.2165/00002018-200831060-00003.

[87] Navarro VJ, Bonkovsky HL, Hwang SI, Vega M, Barnhart H, Serrano J. Catechins in dietary supplements and hepatotoxicity. Dig Dis Sci 2013;58: 2682-2690. doi: 10.1007/s10620-013-2687-9.

[88] Rossi S, Navarro VJ. Herbs and liver injury: a clinical perspective. Clin Gastroenterol Hepatol 2014; in press. DOI: 10.1016/j.cgh.2013.07.030.

[89] Nadir A, Agrawal S, King PD, Marshall JB. Acute hepatitis associated with the use of a Chinese herbal product, ma-huang. Am J Gastroenterol 1996; $91: 1436-1438$

[90] Reuben A, Koch DG, Lee WM, Acute Liver Failure Study Group. Druginduced acute liver failure: Results of a U.S. multicenter, prospective study. Hepatology 2010;52:2065-2076. doi: 10.1002/hep.23937.

[91] Borum ML. Fulminant exacerbation of autoimmune hepatitis after the use of Ma Huang. Am J Gastroenterol 2001;96:1654-1655.

[92] Skoulidis F, Alexander GJ, Davies SE. Ma huang associated acute liver failure requiring liver transplantation. Eur ] Gastroenterol Hepatol 2005; 17 : 581-584.

[93] Joshi D, Cross TJ, Wong VS. Acute drug induced hepatitis secondary to a weight loss product purchased over the internet. Nutr ] 2007;6:13.

[94] http://livertox.nih.gov/ShouWuPian.htm, accessed 10 January 2014

[95] Cárdenas A, Restrepo JC, Sierra F, Correa G. Acute hepatitis due to shenmin: a herbal product derived from Polygonum multiflorum. J Clin Gastroenterol 2006;40:629-632. doi: 10.1097/00004836-20060800000014.

[96] Panis B, Wong DR, Hooymans PM, De Smet PA, Rosias PP. Recurrent toxic hepatitis in a Caucasian girl related to the use of Shou-Wu-Pian, a Chinese 
herbal preparation. J Pediat Gastroenterol Nutr 2005;41:256-258. doi: 10.1097/01.MPG.0000164699.41282.67.

[97] Jung KA, Min HJ, Yoo SS, Kim HJ, Choi SN, Ha CY, et al. Drug-induced liver injury: Twenty five cases of acute hepatitis following ingestion of Polygonum multiflorum Thun. Gut Liver 2011;5:493-499. doi: 10.5009/ gnl.2011.5.4.493

[98] Valente G, Sanges M, Campione S, Bellevicine C, De Franchis G, Sollazzo R, et al. Herbal hepatotoxicity: a case of difficult interpretation. Eur Rev Med Pharmacol Sci 2010;14:865-870.

[99] But PP, Tomlinson B, Lee KL. Hepatitis related to the Chinese medicine Shou-wu-pian manufactured from Polygonum multiflorum. Vet Hum Toxicol 1996;38:280-282.

[100] Park G], Mann SP, Ngu MC. Acute hepatitis induced by Shou-Wu-Pian, a herbal product derived from Polygonum multiflorum. J Gastroenterol Hepatol 2001;16:115-117. doi: 10.1046/j.1440-1746.2001.02309.x.

[101] Battinelli L, Daniele C, Mazzanti G, Mastroianni CM, Lichtner M, Coletta S, Costantini S. New case of acute hepatitis following the consumption of Shou Wu Pian, a Chinese herbal product derived from Polygonum multiflorum. Ann Intern Med 2004;140:587-588.

[102] Laird AR, Ramchandani N, deGoma EM, Avula B, Khan IA, Gesundheit N. Acute hepatitis associated with the use of an herbal supplement (Polygonum multiflorum) mimicking iron-overload syndrome. Clin Gastroenterol 2008;42:861-862. doi: 10.1097/MCG.0b013e3181492515

[103] Furukawa $M$, Kasajima $S$, Nakamura $Y$, Shouzushima $M$, Nagatani $N$, Takinishi A, et al. Toxic hepatitis induced by Show-Wu-Pian, a Chinese herbal preparation. Inter Med 2010;49:1537-1540. doi: 10.2169/internalmedicine.49.3509.

[104] Aiba T, Takahashi T, Suzuki K, Okoshi S, Nomoto M, Uno K, et al. Liver injury induced by a Japanese herbal medicine, sairei-to (TJ-114, Bupleurum and Hoelen combination, Chai-Ling-Tang). J Gastroenterol Hepatol 2007;22: 762-763. doi: 10.1111/j.1440-1746.2006.03373.x

[105] Tsuda T, Yashiro S, Gamo Y, Watanabe K, Hoshino T, Oikawa T, et al. Discrepancy between clinical course and drug-induced lymphocyte stimulation tests in a case of saireito-induced liver injury accompanied by Sjögren syndrome. J Altern Complement Med 2010;16:501-505. doi: 10.1089/ acm.2009.0183

[106] Cohen SM, Heywood E, Pillai A, Ahn J. Hepatotoxicity associated with the use of White Flood, a nutritional supplement. Practical Gastroenterology 2012; October issue:45-48.

[107] Itoh S, Marutani K, Nishijima T, Matsuo S, Itabashi M. Liver injuries induced by herbal medicine, Syo-saiko-to (xiao-chai-hu-tang). Dig Dis Sci 1995;40: 1845-1848. doi: 10.1007/BF02212712.

[108] Hsu LM, Huang YS, Tsay SH, Chang FY, Lee SD. Acute hepatitis induced by Chinese hepatoprotective herb xiao-chai-hu-tang. J Chin Med Assoc 2006; 69:86-88. doi: 10.1016/S1726-4901(09)70119-4.
Teschke R.: Traditional Chinese medicine induced liver injury

[109] Teschke R, Wolff A, Frenzel C, Schwarzenboeck A, Schulze J, Eickhoff A. Drug and herb induced liver injury: Council for International Organizations of Medical Sciences scale for causality assessment. World J Hepatol 2014; 6:17-32.

[110] Chau TN, Cheung WI, Ngan T, Lin J, Lee KW, Poon WT, et al. Causality assessment of herb-induced liver injury using multidisciplinary approach and the Roussel Uclaf Causality Assessment Method (RUCAM). Clin Toxico (Phila) 2011;49:34-39. doi: 10.3109/15563650.2010.537662.

[111] Teschke R, Schulze J, Schwarzenboeck A, Eickhoff A, Frenzel C. Herbal hepatotoxicity: suspected cases assessed for alternative causes. Eur J Gastroenterol Hepatol 2013;25:1093-1098.

[112] Teschke R, Frenzel C, Wolff A, Eickhoff A, Schulze J. Drug induced liver injury: accuracy of diagnosis in published reports. Ann Hepatol 2014;13: 248-255.

[113] Zhang L, Yang X, Sun Z, Qu Y. Retrospective study of adverse events of Polygonum multiflorum and risks control. Zhongguo Zhong Yao Za Zhi 2009;34:1724-1729.

[114] Sangsuwan C, Udompanthurak S, Vannasaeng S, Thamlikitkul V. Randomized controlled trial of Tinospora crispa for additional therapy in patients with type 2 diabetes mellitus. J Med Assoc Thai 2004;87:543546.

[115] Björnsson ES, Bergmann OM, Björnsson HK, Kvaran RB, Olafsson S. Incidence, presentation and outcomes in patients with drug-induced liver injury in the general population of Iceland. Gastroenterology 2013;144: 1419-1425. doi: 10.1053/j.gastro.2013.02.006.

[116] Ko RJ. Adulterants in Asian patent medicines. N Engl J Med 1998;339:847.

[117] Zhang L, Yan J, Liu X, Ye Z, Yang X, Meyboom R, et al. Pharmacovigilance practice and risk control of Traditional Chinese Medicine drugs in China: Current status and future perspective. J Ethnopharmacol 2012;140:519525. doi: 10.1016/j.jep.2012.01.058.

[118] Son HS, Kim GS, Lee SW, Kang SB, Back JT, Nam SW, et al. Toxic hepatitis associated with carp juice ingestion. Korean J Hepatol 2006;12:103-106.

[119] Mukai H, Watanabe T, Ando M, Katsumata N. An alternative medicine, Agaricus blazei, may have induced severe hepatic dysfunction in cancer patients. Jpn J Clin Oncol 2006;36:808-810.

[120] Chan DW, Yeung CK, Chan MK. Acute renal failure after eating raw fish gall bladder. BMJ 1985:290:897. doi: 10.1136/bmj.290.6472.897.

[121] Xuan BH, Thi TX, Nguyen ST, Goldfarb DS, Stokes MB, Rabenou RA. Ichthyotoxic ARF after fish gallbladder ingestion: a large case series from Vietnam. Am J Kidney Dis 2003;41:220-224. doi: 10.1053/ ajkd.2003.50008.

[122] Kung SW, Chan YC, Tse ML, Lau FL, Chau TL, Tam MK. Acute renal failure and hepatitis following ingestion of carp gallbladder. Clin Toxicol (Phila) 2008;46:753-757. doi: 10.1080/15563650701687450. 